Utah State University

DigitalCommons@USU

\title{
The Use of a Discrimination Training Procedure to Teach Mand Variability to Children with Autism
}

\author{
Matthew T. Brodhead \\ Utah State University
}

Follow this and additional works at: https://digitalcommons.usu.edu/etd

Part of the Special Education and Teaching Commons

\section{Recommended Citation}

Brodhead, Matthew T., "The Use of a Discrimination Training Procedure to Teach Mand Variability to Children with Autism" (2014). All Graduate Theses and Dissertations. 2301.

https://digitalcommons.usu.edu/etd/2301

This Dissertation is brought to you for free and open access by the Graduate Studies at DigitalCommons@USU. It has been accepted for inclusion in All Graduate Theses and Dissertations by an authorized administrator of DigitalCommons@USU. For more information, please contact digitalcommons@usu.edu.

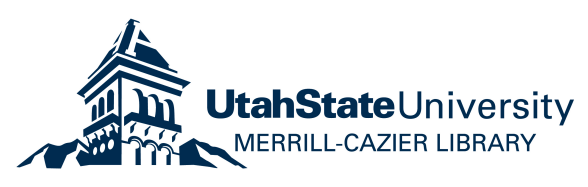


THE USE OF A DISCRIMINATION TRAINING PROCEDURE TO TEACH MAND

VARIABILITY TO CHILDREN WITH AUTISM

by

Matthew T. Brodhead

A dissertation submitted in partial fulfillment

of the requirements for the degree

of

DOCTOR OF PHILOSOPHY

in

Disability Disciplines

Approved:

Thomas S. Higbee

Major Professor

Charles L. Salzberg

Committee Member

Ronald B. Gillam

Committee Member
Timothy A. Slocum

Committee Member

Lillian K. Durán

Committee Member

Mark R. McLellan

Vice President for Research and

Dean of the School of Graduate Studies

UTAH STATE UNIVERSITY

Logan, Utah 
Copyright (C) Matthew T. Brodhead 2014

All Rights Reserved 
ABSTRACT

The Use of a Discrimination Training Procedure to Teach

Mand Variability to Children with Autism

by

Matthew T. Brodhead, Doctor of Philosophy

Utah State University, 2014

Major Professor: Dr. Thomas S. Higbee

Department: Special Education and Rehabilitation

Repetitive behavior and delays in communication are core deficits of autism spectrum disorder. As a result, individuals with autism often engage in repetitive verbal behavior, and they may not vary their verbal behavior, even when the situation demands it. The purpose of this study was to investigate the effects of a script training and discrimination training procedure on mand variability in preschoolers with autism. Participants were taught to vary their vocal mands in the presence of written scripts, a green placemat, and Lag schedule of reinforcement. They were also taught to not vary their vocal mands in the presence of the same written scripts and a red placemat. When the scripts were removed, all three participants continued to engage in varied manding in the presence of the Lag schedule of reinforcement and the green placemat. All three participants also did not vary their mands in the presence of the red placemat. When the Lag schedule of reinforcement was removed, two participants continued to engage in varied responding in the presence of the green placemat and unvaried responding in the 
presence of the red placemat. One participant did not engage in varied responding when the Lag schedule of reinforcement was removed. However, when the Lag schedule of reinforcement was re-introduced, varied responding re-emerged. Finally, all three participants demonstrated mand variability during snack sessions when their peers were present, and they maintained their varied manding after a 2-week follow-up. 
PUBLIC ABSTRACT

The Use of a Discrimination Training Procedure to Teach

Mand Variability to Children with Autism

by

Matthew T. Brodhead, Doctor of Philosophy

Utah State University, 2014

Repetitive behavior and delays in communication are two core deficits of autism. Therefore, the purpose of this study was to determine whether or not three preschoolers with autism would engage in varied or repetitive requests, depending on the situation. Participants were taught to respond in varied or repetitive requests in the presence of green and red placemats, respectively. Written sentences were also available on each placemat to help participants engage in independent requests. When the written sentences were removed, all three participants continued to engage in varied requests in the presence of the green placemat and when reinforcement was provided for response variability; repetitive requests continued in the presence of the red placemat. Two out of three participants continued to engage in varied requests in the presence of the green placemat when reinforcement was provided for all responses, regardless of whether or not they were varied. Finally, all three participants engaged in varied requests during their typical preschool snack session, and they also continue to vary their requests after a 2-week follow-up. Our results indicate that preschoolers with autism can vary the way they make requests, depending on the context. 


\section{ACKNOWLEDGMENTS}

I give my upmost thanks to my mentor and friend, Dr. Tom Higbee, for his support, encouragement, and wisdom throughout the last four years. I thank the rest of my committee, Drs. Tim Slocum, Charles Salzberg, Lillian Durán, and Ron Gilliam, for their scholarly dedication to my professional development. I also thank Dr. Richard W. Malott for teaching me that life is "better living through behavior analysis."

I thank my parents, Christine and Thornie Brodhead, for their love and encouragement, and my brother Drew, for teaching me to push forward when pushing forward seemed impossible. To my grandparents, Mary Lee and Tony Kuchta, I send my love for inspiring me to live a successful and meaningful life. I also thank my mother-inlaw, Diane Dulin, for her love and continuing support.

I would like to thank Nina Gerencser and Jessica Akers for their unprecedented dedication to this project. Without them, this project would not have been possible. I would like to thank Kylee Lewis for taking the primary data, Devin Larsen and Kassidy Reinert for taking IOA, and Amy Heaps for managing the treatment fidelity data.

I give thanks to Tyra Sellers, Alice Austin, Kristen Kelley, Joy Pollard, Daphne Hartzheim, Bethany Contreras, and Lyndsay Nix for their friendship and support. I would also like to acknowledge all of the teachers and education professionals I've worked with over the years; thank you for teaching me about perspective of education on the front-line.

To my friends in Harbor Springs, Kalamazoo, and Logan, I send my love and thanks. I especially thank the late James Dexheimer for introducing me to higher 
education and academic stewardship.

Finally, I would like dedicate this dissertation to my beautiful wife, Hannah.

Without her love, support, and encouragement, this project would not have been possible.

Matthew T. Brodhead 
ABSTRACT iii

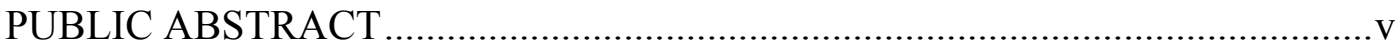

ACKNOWLEDGMENTS ............................................................................

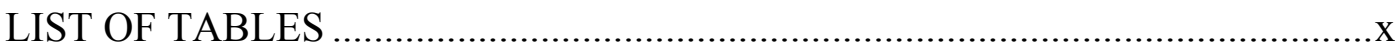

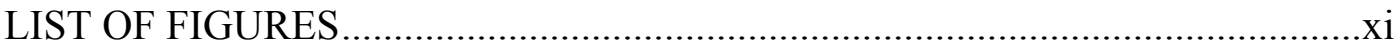

\section{CHAPTER}

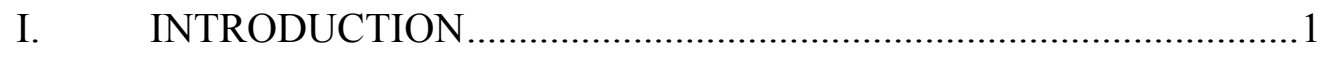

II. LITERATURE REVIEW ..............................................................

Research that Supports Variability as Operant Behavior.......................5

Research on Variability of the Verbal Behavior of

Individuals with Autism ......................................................................

III. METHOD

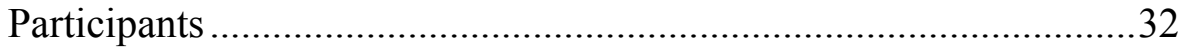

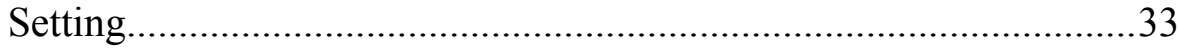

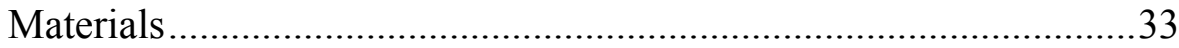

Response Definition and Measurement........................................35

Reliability and Treatment Integrity Measures............................... 37

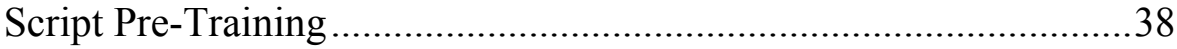

Experimental Design .........................................................................39

Experimental Procedures and Conditions ………………….................40

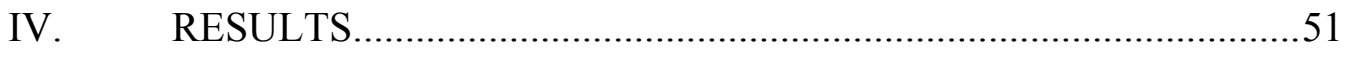

Pre-Experiment Script Training and Fading ......................................51

Treatment Integrity .......................................................................51

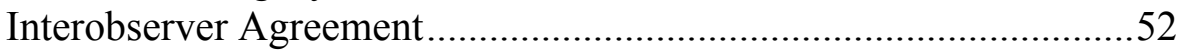

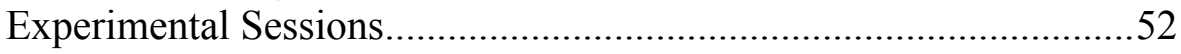

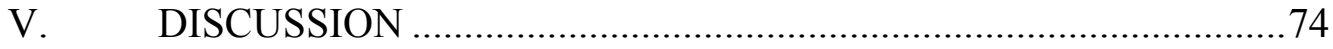


Discriminated Variability with Scripts Present

Discriminated Variability with Scripts Absent

Antecedent Control of Discriminated Variability ..........................8 81

Generalization of Discriminated Variability .................................86

Maintenance of Discriminated Variability .......................................86

Emission of Novel Mand Frames..................................................87

Limitations and Future Directions..............................................8 88

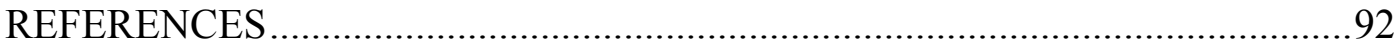

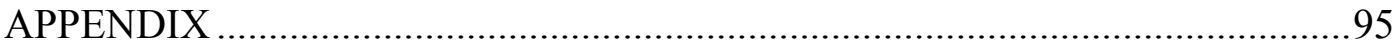

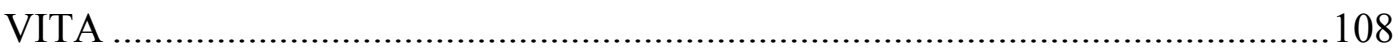




\section{LIST OF TABLES}

Table Page

1 Results of Script Fading Procedures to Increase Mand Variability .................25

2 The Default and New Scripted Frames for Each Participant ............................ 34

3 Sessions to Mastery for the Pre-experiment Script Training and Fading Procedures ...................................................................................... 51 


\section{LIST OF FIGURES}

Figure

1 An example of a placemat with four written scripts 35

2 The number of different mand frames per session ....................................... 53

3 The total number of mand frames per session ............................................ 55

4 Kent's percentage of responses that met schedule requirements..................... 63

$5 \quad$ Kent's cumulative number of responses of each mand frame ......................... 64

6 Gus's percentage of responses that met schedule requirements .......................65

7 Gus's cumulative number of responses of each mand frame ...........................66

$8 \quad$ Kade's percentage of responses that met schedule requirements .................... 68

9 Kade's cumulative number of responses of each mand frame .......................6 69

10 The cumulative number of Kent's responses of for session 68 ..................... 83 


\section{CHAPTER I}

\section{INTRODUCTION}

Men act upon the world, and change it, and are changed in turn by the consequences of their action (Skinner, 1957, p. 1)

Skinner (1953) described that "any condition or event which can be shown to have an effect upon behavior must be taken into account" (p. 23). By analyzing the controlling variables that are responsible for operant behavior, it may be possible to make future modifications of that behavior of interest as long as it's possible to modify relevant controlling variables.

In some cases, behavior may appear to be random and not under the control of environmental variables. However, research now suggests that variable behavior occurs because the environment has established it as functional operant dimension of behavior (Neuringer, 2002). In other words, an individual may engage in varied responding because he or she has learned to do so. He or she has learned, through contingencies of reinforcement, to respond variably.

As suggested above, variability is learned. Likewise, if an individual has a limited repertoire of response variability, he or she may not be able to adapt to changes in the environment, limiting the usefulness of their behavior. One area of disability study, response variability in children with autism, has been gaining momentum in the applied behavior analysis literature. Children with autism are relevant subject matter for the study of response variability because they often exhibit restrictive or repetitive behavior. Because of this, they often fail to vary between different responses, even when 
the situation demands it. This lack of variability can reduce the probability of contacting reinforcement in the natural environment.

For example, a repertoire of varied responding may be necessary if an individual's first response does not produce a reinforcer. Consider the example of turning on a computer. If pressing the "on" button on a computer does not result in access to reinforcement, an individual with a limited response repertoire may stop responding. However, an individual with a larger response repertoire may engage in additional responses in order to earn access to reinforcement. These responses include checking to see if the computer is plugged in to the wall, taking the computer apart, and/or asking a friend to repair the computer.

Varied responding may also help to increase the probability of contacting reinforcement if the organism enters a novel environment. For example, a student with autism may walk into a new school and attempt to gain someone's attention by raising his or her hand. If that response does not produce access to adult attention, a student with a limited response repertoire may cease responding. However, if the individual had a larger repertoire and a history of reinforcement for response variability, he or she may say, "Excuse me!" or "I need help!" in order to gain access to adult attention.

Varied responding may also help to improve an individual's interactions with peers. For example, if an individual with a limited response repertoire says "Hello, how are you?" repeatedly as each of his or her classmates enters the room, this behavior may be deemed as repetitive, strange, and possibly annoying. However, if that individual engaged in a different response to acknowledge each peer (e.g., nodding his or her head or saying “What's up?”), social stigmatization may be less likely to occur. 
The previous two scenarios describe instances of response variability of verbal behavior. Verbal behavior is unique to other forms of operant behavior because it requires both a speaker who engages in a certain response form and a listener who reinforces that response (Skinner, 1957). For example, a child may use his or her hand to turn on a light, and the behavior of turning on the light would be categorized as a simple, operant response. However, consider another example when that same child says "Mommy, will you turn on the light?" and as a result, the mother willingly walks over to the lamp, flips a switch, and therefore brightens up the room. The response "Mommy, will you turn on the light?" is considered verbal behavior because reinforcement is mediated by another individual (i.e., the mother).

Because a study of verbal behavior involves active manipulation of environmental variables, behavior analytic researchers have applied this approach to language acquisition in individuals with disabilities. For example, Betz, Higbee, Kelley, Sellers, and Pollard (2011) used manding as a framework for teaching response variability to preschoolers with autism. This allowed Betz et al. to isolate variables related to motivation and consequences in order to provide a basic framework for understanding response variability from a verbal behavior perspective. This study helped to set the groundwork for future research that exposed various environmental variables that may be responsible for response variability that occurs under the context of requesting in children with autism. It is this line of research that we seek to highlight in our literature review and to contribute to with our experimental questions.

From basic laboratory experiments on response variability (e.g., Page \& Neuringer, 1985) to applied studies with children with autism (e.g., Betz et al., 2011), our 
understanding of variability continues to grow and change. Below, we provide a brief summary of relevant basic and applied research on operant variability. Then, we review studies that examined response variability in individuals with autism and describe how the results of previous research have laid the foundation for the questions addressed with the current study. Finally, we describe the results and implications of this research and how those results may improve the social and academic outcomes of individuals with autism. 
CHAPTER II

\section{LITERATURE REVIEW}

Neuringer (2002) defined response variability as behavior on a "continuum ranging from repetitive at one end to stochastic [random] at the other" (p. 672). In this literature review, we describe studies that have examined variability at various levels, from the key pecking behavior of a pigeon, dolphins emitting never before seen responses, to block play in children with autism. Each study has examined how environmental variables (e.g., antecedent and consequence manipulations) affect variability using the principles of behavior. That is, all studies aim to understand how environmental manipulations may establish and manipulate variable responding.

\section{Research that Supports Variability as Operant Behavior}

In 1969, Pryor, Haag, and O'Reilly conducted a landmark study where they established novel behavior in dolphins. Specifically, they taught two dolphins to engage in behavior that had never been seen before. Using a combination of reinforcement of novel responses, intermittent reinforcement of previously seen responses, and extinction, researchers established the response class of novel responding by 33 training sessions. Another important component of the study is that researchers reported that they were able to bring novel behavior under stimulus control. That is, the dolphins engaged in novel behavior when the trainer stood in a specific spot. When the trainer stood in other spots, the dolphins did not engage in novel responses. Therefore, Pryor et al. was the first study 
to demonstrate the potential utility of antecedent control (i.e., the position of the trainer) and contingencies of reinforcement in establishing novel responding.

Another notable study on variability was conducted by Page and Neuringer (1985). Page and Neuringer conducted this study in order to examine previous findings that seemed to suggest that certain types of variability could not be established through contingencies of reinforcement (see Schwartz, 1980, Experiment 4; and Schwartz, 1982, Experiment 1). In Experiments 1 and 2, Page and Neuringer demonstrated that if a participant failed to vary, fault could be placed in the experimental preparation and not because contingencies of reinforcement can not establish random behavior. In Experiment 3, Page and Neuringer introduced a Lag x schedule of reinforcement, "where $\mathrm{x}$ represents the number of previous responses the current response must differ from to be reinforced" (Lee, McComas, \& Jawor, 2002). Under a Lag 50 schedule of reinforcement, they demonstrated that pigeons can engage in a response sequence that differed from up to the previous 50 response sequences. In Experiment 4, Page and Neuringer demonstrated that the number of responses a pigeon engages in during a given response sequence (i.e., 4, 6, and 8) can also be expanded and occur randomly under the control of contingencies of reinforcement. Experiment 5 demonstrated that when pigeons were free to vary, but reinforcement was not contingent on response variability, variability was less likely to occur. This condition was compared to conditions when reinforcement was contingent on variability. Again, this demonstrated that response-contingent reinforcement for varied responding was responsible for variable behavior. Finally, Experiment 6 demonstrated that variability could be placed under discriminative control, demonstrating that variability may be controlled by antecedent and consequence 
manipulations. The understanding of antecedent control of variability was also replicated and extended (by examining whether or not variability could be placed under discriminative control) in a later project by Denny and Neuringer (1998).

The above studies highlight basic experimental research that suggests that variability is learned behavior (see Neuringer, 2002 for a review of additional basic research studies that support this hypothesis). This is important because it highlights that, under basic experimental arrangements, antecedent and consequence manipulations can modify the extent to which nonhuman participants vary their responses. In addition to basic research with nonhuman subjects, the effects of environmental manipulations on response variability have also been demonstrated with human participants. In 1973, Goetz and Baer examined the effects of social reinforcement for the block building behavior of three typically developing preschool girls. Specifically, they provided social reinforcement for new response forms that had not occurred within that same session. When reinforcement of novel responses occurred, the number of different block arrangements per session increased. When reinforcement was provided for repeat responses, the number of different block arrangements per session decreased. This study demonstrated that variable responding may be established in young children, and it also provided additional evidence that response variability is more likely to occur when variability is reinforced.

In 2012, Miller extended Goetz and Baer (1973) by examining the effects of a Lag 3 schedule of reinforcement on the block building and patterns on a pegboard in three males with autism between the ages of 7 and 9. Miller also examined whether or not response variability could be placed under vocal discriminative control. Using a 
reversal design, during the continuous schedule of reinforcement condition (CRF), all valid forms of block building produced reinforcement. During the vary (VAR) phase, a Lag 3 schedule of reinforcement was in effect. During the repeat (REP) phase, reinforcement was contingent on a response form being the same as one of the previous three response forms. Researchers also introduced a multiple schedule phase where a random number generator determined whether or not the VAR or REP phase was in effect. Then, the multiple schedule phase continued, and the researchers removed relevant vocal discriminative stimuli. Finally, a generalization phase was introduced where researchers tested the effects of the discriminative stimulus to vary during a novel painting activity. This phase resembled the original multiple schedule phase with relevant vocal discriminative stimuli (e.g., "make same" or "make different").

For all three participants, variability increased during the Lag 3 schedule of reinforcement. Also, researchers demonstrated that variable responding could be brought under vocal discriminative control. That is, when researchers provided the discriminative stimulus "make same" or "make different", the participants responded accordingly to the vocal rules. This finding is especially interesting because it demonstrates that children with autism can engage in discriminated response variability. Finally, researchers did not demonstrate novel responding during the generalization condition, suggesting that researchers may need to teach variability for each target activity.

\section{Research on Variability of the Verbal Behavior of Individuals with Autism}

Given that individuals with autism often engage in repetitive, restrictive language, researchers have examined the effects of various procedures on establishing their variable 
verbal behavior. Below, we describe two areas of research, responding variably to social questions and responding variably under the context of requesting items.

\section{Responding Variably to Social Questions}

In 2002, Lee et al. examined the effects of a Lag 1 schedule of reinforcement plus differential reinforcement of alternative behavior (DRA) on the answers to social questions in 3 male children with autism. This was the first study to examine the effects of a Lag schedule of reinforcement in an applied setting. For each participant, researchers identified a social question that reliably resulted in the participant providing the same answer (e.g., question: "How are you?", answer: "I'm fine”). Using a multiple baseline with embedded reversals design, Lee et al. measured the number of varied vocal responses to the social question. A varied vocal response was defined as a response that differed from the previous response beyond that of verb tense or sentence structure.

During the baseline (DRA only), appropriate responses to social questions were reinforced. During the intervention condition (Lag 1/DRA), reinforcement was delivered if the participant's response was different than the previous response. If a grammatically incorrect response occurred, the researcher provided a vocal prompt and provided reinforcement if the prompt elicited a correct response. Generalization sessions were also conducted across all conditions.

For two of the three participants (Charles and David), the percentage of trials with varied and appropriate responses was higher during intervention (Lag 1/DRA) than in baseline (DRA only). For one participant, Larry, varied appropriate remarks did not increase even when Lee et al. added an additional intervention that included vocal 
prompting that was faded along a progressive time delay. The results of this study indicate that contingencies of reinforcement can control variable responding in some individuals with autism. The results also suggest that a Lag 1/DRA schedule may not be an appropriate intervention in all cases. Lee et al. also reported that Charles and David emitted novel response forms that appeared to be under the control of various items in the room. For example, when Charles was in the classroom, he engaged in the response "I like to play with toys" and when he was in the gym, he responded "I like to ride the bicycle." Since the participants routinely requested access to the items they described in the sessions, researchers hypothesized that the answers to social questions were functioning as mands. Regardless, the presence of the items appeared to have discriminative control over the response forms of two of the three participants.

In 2006, Lee and Sturmey directly tested the hypothesis that the presence of preferred stimuli in the environment may influence varied responding. Specifically, they asked whether or not having 0,5 , or 10 preferred items available would affect responses to the question "What do you like to do?" in 3 teenage males with autism. Lee and Sturmey evaluated this hypothesis using a multi-element design (i.e., 0,5 , or 10 preferred items available) that was embedded within a reversal design to test the number of correct responses to "What do you like to do?" Researchers also measured novel responses. During baseline (Lag 0), all appropriate responses were reinforced. During intervention (Lag 1), responses were reinforced if it differed from the previous response by more than just grammatical changes (e.g., verb tense, articles). Ten preferred items were identified using a multiple stimulus without replacement (MSWO; DeLeon \& Iwata, 1996) preference assessment. 
For 2 of the 3 participants (Omel and Ricardo), the Lag 1 schedule of reinforcement produced more varied vocal responding than the Lag 0 schedule of reinforcement. For one participant (Brendan), the Lag 1 schedule of reinforcement did not produce varied responding. These results replicated the findings of Lee et al. (2002). For all three participants, the presence of preferred items did not have an effect on variable responding. This suggests that items in the environment may not control variable responding unless that control has been explicitly established.

It is worth noting that Susa and Schlinger (2012) also replicated and extended Lee et al. (2002) in one 7 year-old male with autism. In their study, researchers extended the schedule of reinforcement from a Lag 1 schedule to a Lag 3 schedule, and they also conducted systematic preference assessments and limited the social question to "How are you?" in order to mitigate the possibility that various items in the room may control participant responding. At the end of the study, the participant alternated between four different responses under the Lag 3 schedule of reinforcement. Like results obtained by Lee et al. (2002) and Lee and Sturmey (2006), this study provides further evidence that some individuals with autism can learn to engage in varied responding when the contingencies of reinforcement require it.

Lee (2007) extended previous work on response variability by testing the effects of script training and fading on responses that occurred during a three-turn conversation. Unlike previous research studies, a varied response was scored if it differed from a response during the same turn in the previous conversation. Consider an example where the first answer to the first conversational question of the day elicited the response "I am doing well, thank you." Then, when the conversation was held later that day, if the 
participant's answer to the question was "I am doing well, thank you" a varied response was not scored. However, if the participant said "I have a headache", a varied response was scored. Using a reversal design, Lee taught participants to respond to 27 different scripts prior to baseline. Scripts are a type of visual or auditory support that serves as a discriminative stimulus for the individual to engage in a specific response. Like a prompt, they are temporary stimuli that are eventually faded in order to allow features of the environment to control responding. After a Lag 0 (baseline) was implemented, scripts were introduced and faded once participants demonstrated independent and stable responding. Then, Lee reintroduced the Lag 0 condition. After demonstrating that script training alone was not a sufficient procedure to establish response variability, Lee introduced a Lag 1 schedule of reinforcement that also included a repeated-trials prompting procedure. That is, if a participant did not engage in a varied response, the conversational turn was repeated up to 5 times until the participant responded variably.

For all three participants, varied responding was higher during the script training and fading condition than during baseline $(\operatorname{Lag} 0)$. When the scripts were removed, responding decreased to baseline levels. As a result, a Lag 1 plus repeated-trials condition was implemented (without scripts present), and increased and responding resembled that of the scripting phase. The results of this study were consistent with those obtained previously by Lee et al. (2002) and Lee and Sturmey (2006). That is, individuals with disabilities may not vary their verbal behavior unless contingencies of reinforcement require it. Therefore, script training alone may not be an adequate procedure to establish response variability. 
It is worth noting that Lee (2007) suggested that responding possibly returned to baseline levels after script training because the scripts may have exerted discriminative control over participant behavior. That is, it is possible that each script served as a discriminative stimulus to engage in a specific response because reinforcement was contingent upon correct responding when scripts were present. Therefore, it is possible that when the scripts were present, the scripts controlled participant responding to the point where they were necessary for responding to occur. When the scripts were removed, responding decreased. Therefore, the scripts may have unintentionally gained discriminative properties. Lee suggested that future studies should examine how to transfer stimulus control from scripts to stimuli that are more likely to be found in social environments.

\section{Responding Variably Under the Context of Requesting}

As with responding to social questions, individuals with autism often engage in minimal response variability when making requests (manding). For example, a child with a limited response repertoire may engage in the same mand form "I want $" 10$ consecutive times without engaging in a different mand form (e.g., "I would like

"). Because of this, researchers have begun to develop strategies to promote mand variability in children with autism. As mentioned above, variability is important because it allows for an individual to engage in a different response when the first response does not produce reinforcement. Aside from the benefits of varied manding, manding preparations also provide a context that allows experimenters to control motivational variables responsible for verbal behavior. That is, researchers can withhold 
access to preferred items and as a result, participants may be more likely to engage in verbal behavior to earn access to those items. Because of this, the context of requesting snack items serves as an appropriate preparation to examine strategies to achieve independent and varied verbal behavior in children with autism. This arrangement also has applied importance, since early-intervention autism programs often focus on improving verbal behavior during snack settings. Below, I describe three studies that evaluated the effects of three different types of script training procedures on mand variability in preschoolers with autism.

In 2011, Betz et al. examined the effects of auditory scripts and sequential script fading on mand variability in preschoolers with autism. Each script was an auditory device (hereafter referred to as an auditory script) that had a colored dot that was attached to a button. When the button was pressed, the audio device played the correct response. (e.g., "Can I please have ," "May I have some ," and "I would like "). Before teaching participants to respond to the auditory scripts, Betz et al. exposed each participant to a baseline condition to measure response variability (i.e., the number of different mand frames). In order for a mand frame to be considered "different" from another mand frame, it had to be different by more than the researcher's name, nouns that correspond to available edible items, rearranging the word order, or adding or deleting "please." This same measure was used throughout the remainder of the study. During the baseline condition, all complete mand frames (e.g., "I would like ") were reinforced and incomplete mand frames (e.g., "Skittles, please") or gestures were not reinforced. Then, participants were exposed to an extinction condition in order to test whether or not extinction prior to teaching would increase mand 
variability. In extinction, the first response of each full mand frame was reinforced, and additional responses of that same mand frame were not reinforced for the remainder of the session. For example, the first time a participant said "Can I have___, that response was reinforced. The second time "Can I have___ occurred during that same session, it was not reinforced. Following extinction, Betz et al. taught each participant to respond to each auditory script once at a time, and they used a backwards fading technique to fade each script after $90 \%$ accuracy for one session. For example, at 90\% accuracy with the script "Can I please have ," the script was faded to "Can I please," then "Can I," then "Can." During the script training condition, all complete mand frames were reinforced, and if no responding occurred for 30-s, researchers manually prompted the participant activate the script. After each script training and fading condition (scripts were completely faded), Betz et al. exposed each participant to baseline and extinction phases to test the effects of varied responding when all responses were reinforced (baseline), and when only the first response of each mand frame was reinforced (extinction). Following the final baseline and extinction condition, generalization and follow-up sessions were conducted to test the effects of the script training and fading procedure in a novel environment and after a passage of 1 to 2 weeks. Both Jillian and Travis engaged in varied manding when extinction of repetition contingencies were in place and three new mand frames had been learned via the script fading intervention. However, Drew did not engage in varied manding after script training and fading when extinction of repetition contingencies were present, and therefore, Betz et al. implemented an alternative intervention (otherwise known as multiple script presentation), in order to improve Drew's mand variability. In this 
condition, all three audio scripts (same as the previous three scripts taught during the script training phases) were placed in front of Drew. The research assistant prompted Drew to push one of the audio scripts in a quasi-random order. The research assistant also prompted Drew to use a different script if he engaged in the same mand frame two times in a row. Scripts were faded once Drew's independent responding reached $90 \%$ accuracy for one session. Scripts were faded faster during this condition, from full script to the first word, then to the colored dot on his placemat. During the first multiple script presentation condition, which lasted 21 sessions, Drew's responding ranged from 2 to 5 different mand frames per session, with the condition ending as data were trending upward towards 4 different mand frames per session. During a return to baseline, which lasted for three sessions, Drew consistently engaged in 1 different mand frame per session. Due to low levels of responding during this baseline phase, the multiple script presentation phase was re-introduced. This condition lasted for 14 additional sessions, and responding was variable from 2 to 5 different mand frames per session. During the final condition, generalization, the colored dots remained in place on Drew's placemat in order to cue variability. In this condition, Drew's responding remained stable at 3 different mand frames per session across three sessions.

In summary, Drew did not engage in varied manding during initial baseline and extinction conditions. However, at the end of the study Drew varied his manding, but only in the presence of specific visual cues (colored dots on his placemat). Without these visual cues, Drew engaged in only 1 different mand frame for each session (as evidenced by the final baseline condition). This suggests that the visual cues (i.e., colored dots) likely controlled mand variability. Drew's outcome was different than Jillian and Travis' 
results, who both demonstrated increased levels of mand variability without the use of visual supports at the end of the study. The results of this study indicated that building a response repertoire of different mand frames may be helpful in establishing mand variability for some preschoolers with autism, and a contingency that demands variability may also be necessary. The results also suggested that some individuals with autism (e.g., Drew) may need additional visual supports in order for mand variability to occur. Based on the effectiveness of the multiple script training intervention used by Betz et al., Sellers (2011) asked whether or not teaching multiple scripts simultaneously would produce more reliable and faster acquisition of mand variability than teaching the scripts sequentially as was done in Betz et al. (2011). Instead of teaching each participant to respond to a single auditory script at a time, Sellers used multiple script training to teach the participant to respond to textual scripts (typed scripts presented on pieces of paper). During multiple script training sessions, the research assistant sequentially presented each script to the research participant, one script at a time. Once the script was presented, the participant had 3-s to repeat the script. If the participant responded correctly (e.g., they said "I would like cheeto" in the presence of the "I would like script) within $3 \mathrm{~s}$, reinforcement was delivered. If the participant did not respond within $3 \mathrm{~s}$, the research assistant physically prompted the student to touch the script. If no responding occurred within 3-s of the physical prompt, the research assistant physically prompted the student to touch the script and the research assistant also modeled the appropriate vocal response. Researchers faded scripts when the participant independently (without prompts) engaged in scripted responding at 100\% accuracy across 2 consecutive sessions. Scripts were faded in a fashion similar to that of Betz et al.. That is, 
researchers faded the script "I would like " to "I would" to "I" once the participant met fading criteria. During the multiple script training and fading conditions, all complete mand frames were reinforced. Baseline and extinction of repetition conditions were identical to those used by Betz et al., and Sellers also introduced a baseline generalization session that was identical to the generalization session Betz et al. used at the end of their study.

All three participants did not vary their mands when the scripts were removed and extinction conditions were in effect, therefore Sellers et al. used additional interventions to promote mand variability. For both Nicodemus and Barstow, a simultaneous script training procedure was introduced in order to teach participants to respond variably when visual supports were present. This procedure resembled that of baseline, when all mands were reinforced, except the first letters of each script remained in front of the participant on their placement throughout the session. Both Nicodemus and Barstow engaged in independent mand variability when the scripts were present, and when the scripts were removed, responding reduced to baseline (Nicodemus) or lower levels (Barstow). Therefore, the scripts (the first letter of each script) remained in place for the remainder of the study. That responding decreased to lower levels when the scripts were removed suggests that the scripts were likely functioning as discriminative stimuli for varied manding.

The third and final participant, Michelle was exposed to simultaneous script training, except Michelle's script use was prompted. This prompting procedure was similar to that of multiple script training. During this condition, which consisted of nine sessions, Michelle reliably engaged in 3 different mand frames each session. Then, 
researchers continued with the simultaneous script presentation condition, except they no longer provided prompts for Michelle to vary. When prompts were removed, responding ranged from one to three different mand frames across nine sessions, and it stabilized at two different mand frames per session. Following this condition, a progressive Lag 2 schedule was introduced. This phase was identical to the previous phase, except a progressive Lag schedule was in place. That is, once Michelle engaged in a mand frame, she needed to engage in two other different mand frames before that original mand frame was reinforced. Unfortunately, Michelle was never able to contact the contingencies in the progressive Lag 2 schedule, and responding remained at one different mand frame across three sessions. Then, researchers hypothesized that scripts served as discriminative stimuli for reinforcement for using scripted mands. Because of this, an additional procedure was introduced where each of the three scripts were placed in front of Michelle (similar to that of simultaneous script presentation), and when she engaged in a scripted response, that script was removed. At this point, the two remaining scripts remained in front of Michelle on her placemat. After engaging in a different scripted response, that script was removed, leaving one script in place. After she engaged in the final scripted response, the script was removed, and all three scripts were represented on her placemat in a random order. If at any case during this condition she engaged in a scripted mand frame that was not present on her placemat, it was not reinforced. During this condition, which lasted for five sessions, responding ranged from three to four different mand frames for each session, and it eventually stabilized at three different mand frames per session. When the scripts were removed, Michelle did not engage in any complete mand frames, demonstrating that the scripts were controlling 
variable manding. Michelle's generalization condition lasted for eight sessions, and the previously described procedure remained in place. During this condition, responding ranged from zero to three different mand frames per session, and it stabilized at three different mand frames per session. During 2- and 4- week follow-ups (where the previous intervention remained in place), Michelle engaged in three different mand frames for each session. In summary, Michelle engaged in greater mand variability at the end of the study, but only with the manipulation of visual supports combined with extinction procedures described above. When these supports were removed, responding ceased (as demonstrated in the no script probe), suggesting that visual supports played a role in controlling mand variability. Furthermore, Michelle demonstrated greater sensitivity to extinction than previous participants, and as a result, extinction was unable to promote mand variability unless visual cues were in place. This suggests that extinction, alone, even after participants have acquired additional response forms, may not be a sufficient strategy for prompting mand variability in some cases.

It is worth noting that the teaching preparations used by Sellers may have unintentionally established stimulus control for variability. That is, each researcher presentation of the script may have served as a discriminative stimulus to respond, and when this procedure ceased, so did response variability. That researcher presentation of scripts gained discriminative control may be further evidenced by the difficulty Sellers had in fading scripts for all three participants. This was further evidenced by the observed decrease in mand variability during the no-script probes. However, since the experimenters did not experimentally examine the possible mechanisms controlling mand 
variability (e.g., conducting a component analysis of possible controlling variables), though the exact mechanisms controlling mand variability are unknown.

Due to the small increase in variability some participants in Betz et al. (2011) and Sellers (2011), the inability to completely fade scripts for 4 of 6 participants across those two studies, and the potential adverse affects of extinction (see results for Michelle above), Kelley (2013) tested whether or not antecedent strategies alone, in combination with simultaneous script training and fading, would result in an increase in mand variability in preschoolers with autism. With simultaneous script training, all three textual scripts were presented in front of the participant, along with a fourth script that corresponded to the participant's default mand frame (i.e., the mand frame the participant commonly used to request items). This arrangement was different from previous studies in that all 4 scripts were available at the same time to use, whereas in Sellers, all scripts were taught during the same session, except the experimenter placed them on the table one script at a time.

Building on the results of Sellers (2011), Kelley (2013) taught each of the three participants to respond variably by placing four text-based mand scripts in front of each participant and pointing to each script in a predetermined order. Specifically, after the instruction "It's time for snack" was given, if the participant did not engage in a scripted mand after $5 \mathrm{~s}$, the researcher pointed to one of the four scripts. If the participant did not engage in a prompted response, the researcher engaged in a gesture prompt, physically guided the participant to touch the script, and then provided a verbal model of the response. The script training concluded when the participant engaged in independent responses $80 \%$ of the time, across two sessions. Following script training, script fading 
was introduced. During script fading, researchers simultaneously faded scripts when the participant engaged in $80 \%$ independent responding across two sessions. If, at any point, a participant responded with the same mand frame two times in a row, Kelley physically prompted the participant to touch and engage in a different scripted mand frame. Baseline conditions also resembled those in the previous two studies.

Brody engaged in varied manding at the end of the study, however, antecedent manipulations, alone, were not sufficient in establishing mand variability. As a result, researchers implemented an extinction procedure and Brody then demonstrated elevated levels of mand variability. The next participant, Olivia, did not engage in independent mand variability when the scripts were removed. Like Brody, an extinction component was introduced, and the first letter of each script remained in front of Olivia on her placemat. This phase resembled the tear-off procedure that Sellers (2011) used for Michelle. In summary, Olivia engaged in varied manding at the end of the study, but only with the aid of supplemental (scripted) support. When the scripts were removed, even with extinction in place, she routinely used only 1 mand frame per session. These results suggest that additional visual supports were necessary in order to cue mand variability.

Natasha engaged in independent mand variability at the end of the study. However, she required additional modifications to the experimental arrangement described above. Due to Natasha's low levels of responding following the script training and fading conditions, Kelley (2013) re-introduced a script training condition. Prompting remained the same for this condition, but the textual scripts were different. Specifically, the first letter of each script was placed in front of the student, along with lines that corresponded to the remaining words in the script (e.g., " $\mathrm{C}$ " for "Can I 
have "). This was successful in producing varied manding. Then the lines were removed, but the first letter of each script remained. This phase lasted for two sessions, and independent variability continued. At this point, baseline was reintroduced without scripts or experimenter prompting, for three sessions, and responding decreased to 1 different mand frame for each session. Then, researchers re-introduced the previous phase, where the first letter of each script was present. Following this condition, the first letter of each script was available, except researchers discontinued prompting procedures. This condition lasted for seven sessions, and responding varied from 1 to 3 different mand frames for each session, and eventually decreased and stabilized to 1 different mand frame for each session. Then, Kelley re-introduced the point-prompting procedure for the next phase, and Natasha reliably engaged in four different mand frames for each of the three sessions.

At this point, Kelley (2013) hypothesized that Natasha's responding was under the control of the point-prompt. To test this hypothesis, they removed the placemat and scripts from in front of Natasha and provided point-prompts to empty locations on the table where the scripts had previously been located. During this condition, she reliably engaged in three different mand frames for each of the three sessions. Then, Kelley conducted a short generalization phase, which was similar to the previous phase except that it occurred at the snack table. During the two generalization sessions, Natasha engaged in four and three different mand frames, respectively. Though Kelley was able to demonstrate that researcher prompting was controlling mand variability, it was determined that this was not an appropriate clinical intervention because it did not support Natasha's independent responding. Therefore, they reintroduced the first letter of 
each script and continued to prompt as necessary. Next, Kelley introduced an extinction condition. Kelley made the decision to introduce extinction because she had demonstrated that antecedent manipulations, alone, would not increase mand variability. Due to the success of extinction promoting mand variability in previous studies (e.g., Betz et al., 2011) and the results of Sellers (2011) that suggested that antecedent and consequence manipulations may promote mand variability, extinction served as a viable option for increasing response variability. In this condition, they reinforced the first response of each complete mand frame, but put subsequent responses of that mand frame on extinction for the remainder of the phase. For example, the first time Natasha said "I would like a cookie," it was reinforced. Subsequent mand frames of "I would like " were not reinforced. Independent mand variability was observed in this phase. Then, baseline was reintroduced for four sessions, and responding decreased to baseline levels. The extinction phase was reintroduced, and for six sessions, responding varied from 1 to 4 different mand frames for each session. During the final generalization probe, which resembled that of the extinction phases, Natasha engaged in 6 different mand forms.

In summary, Natasha engaged in more varied manding at the end of the study, but only with antecedent and consequence manipulations. That is, when extinction was not in place, less variability occurred than when extinction was in place. Also, researchers demonstrated that researcher prompting (i.e., the gesture prompt) controlled mand variability. Though this prompt was deemed to be clinically inappropriate, it provides additional information about how teaching preparations may establish additional, unwanted variables that control varied responding. 
In summary, the degree to which participants varied at the end of each study was different across participants. See Table 1 for a summary of results. Those who varied independently without supplemental $S^{\mathrm{D}}$ (i.e., script/other visual cues) support engaged in a larger range of mand frames than those who needed additional $\mathrm{S}^{\mathrm{D}}$ assistance to cue variability. Specifically, during extinction of repetition and generalization and follow up phases in Betz et al. (2011), the number of different mand frames ranged from 0 to 6,1 to 5 for Jillian and Travis, respectively. During extinction of repetition and generalization phases in Kelley (2013), Brody's manding ranged from 3 to 7 mand frames and Natasha's manding ranged from 1 to 6 mand per session.

Those with who did not vary without $\mathrm{S}^{\mathrm{D}}$ support were more likely to engage in a smaller range of variability. Specifically, Michelle's manding ranged from 0 to 3 different mand frames per session, with only $20 \%$ of sessions with 0 mands, in

Table 1

Results of Script Fading Procedures to Increase Mand Variability

\begin{tabular}{lccc}
\hline Study & $\begin{array}{c}\text { Independent } \\
\text { Variability }\end{array}$ & $\begin{array}{c}\mathrm{S}^{\mathrm{D}} \text { with } \\
\text { Extinction }\end{array}$ & $\begin{array}{c}\mathrm{S}^{\mathrm{D}} \text { without } \\
\text { Extinction }\end{array}$ \\
\hline Betz et al. (2011) & Jillian* & - & - \\
& Travis* & - & - \\
& - & - & Drew* \\
Sellers (2011) & - & Michelle & - \\
& - & - & Nicodemus* \\
Kelley (2013) & - & - & Barstow \\
& & - & - \\
& Brody* & - & - \\
\hline
\end{tabular}

*Novel responding observed 
generalization and maintenance phases, and Nicodemus and Barstow's manding ranged from 2 to 4 and 3 to 4 , respectively. Olivia's manding remained steady at 3 mand frames for each session. Finally, Drew engaged in 3 to 6 mand frames during extinction of repetition and follow up, serving as the only participant across the three studies who reliably engaged a range of manding that was similar to those who varied without supplemental support. Michelle and Olivia varied with the aid of $\mathrm{S}^{\mathrm{D}}$ support with extinction of repetition, and Drew, Nicodemus, and Barstow varied with $\mathrm{S}^{\mathrm{D}}$ support without extinction of repetition.

The results of each study suggest that the use of script training can facilitate mand variability in some individuals with autism. However, the degree to which participants varied without additional supplemental support (e.g., gesture prompts and visual aids) is mixed. One possible explanation for why participants did not engage in independent variability (i.e., variability without the use of visual aids) is that the research preparations did not effectively transfer stimulus control from the scripts to the natural environment. In each of the three studies on mand variability mentioned above, participants engaged in varied responding during initial script training sessions, but when the researchers removed the scripts, variability ceased or was not stable over time for most participants. This possibly occurred because scripts gained strong stimulus control over behavior because, during script training sessions, reinforcement for varied responding only occurred when the scripts were present. It is also possible that certain teaching procedures may have inadvertently established stimulus control over mand variability. For example, in Sellers, the instructor placed each script in front of the participant one at a time. It is possible that the researcher presentation of scripts served as an $\mathrm{S}^{\mathrm{D}}$ to 
respond. Researcher presentation may have exerted enough control to where it was difficult to transfer control to the natural environment. This is evidenced by the results of Sellers where all three participants required supplemental visual support, via the first letter of each script, to cue variability. Also, Kelley demonstrated that, when scripts were removed, Natasha's mand variability could be controlled by the researcher's pointprompting. Therefore, it is possible that scripts or point prompts served as discriminative stimuli for variability, and when they were removed, variable responding because the relevant $\mathrm{S}^{\mathrm{D}} \mathrm{S}$ were no longer present.

Given the possibility that script training procedures may not establish appropriate discriminative control for varied responding when those scripts are removed, a procedure that aims to establish discriminative control of varied responding when scripts are absent may be worth exploring. That is, a treatment package of simultaneous script training and fading plus discrimination training procedures may help to establish the necessary conditions for variability when the scripts are removed. With a discrimination training procedure where contingencies of reinforcement that support either response variability or response repetition alternate to establish a discriminative stimulus for response variability, the appropriate conditions for variability may be established. This may help to produce conditions under which variability will occur in the absence of scripts. It is possible that participants may learn to respond variably in the presence of a discriminative stimulus that is not tied to a specific script and response form. That is, the discriminative stimulus for variability may be represented by a general color or symbol instead of a script with one-to-one correspondence to a specific response form. With 
proper training, this discriminative stimulus may serve as a "bridge" stimulus that promotes variability when the scripts are removed.

A bridge stimulus may have practical importance because it may allow researchers to program common stimuli into the experimental procedure that may eventually control variable manding at the end of the study. In 1977, Stokes and Baer suggested teaching individuals to respond to a stimulus that is likely to be present during generalization or natural settings may make responding more likely to occur in those settings. The ultimate goal of any applied intervention on verbal behavior would be to transfer stimulus control to naturally occurring variables. Therefore, examining the effects of a bridge stimulus may provide information how to better program common stimuli into teaching and therefore achieve this desired verbal behavior outcomes in children with autism.

Another possible benefit of the bridge stimulus is that it may increase the likelihood of novel responding during test sessions. In previous studies, when researchers faded scripts, all participants engaged in additional mand frames that were not explicitly taught. However, when supplemental $\mathrm{S}^{\mathrm{D}}$ support remained in place, novel responding across participants was mixed. Drew and Nicodemus both engaged in novel responses, while Michelle, Barstow, and Olivia did not engage in novel responding. Therefore, it is possible that an additional benefit of the bridge stimulus is that it may serve as a supplementary support to encourage novel responding.

Conceptually, a discriminative stimulus for varied manding may promote novel responding because it will not be tied to one specific response form. For example, each script has one-to-one correspondence with a desired response, and three or four available 
scripts represent three or four options for responding. With a discriminative stimulus for varied manding present without scripts, participants may be more likely to engage in novel manding because response requirements are no longer associated with specific scripts. The only response requirement would be to vary between different mands, and this response requirement may be best represented by a generalized "bridge" stimulus. Aside from the potential to facilitate the fading of scripts and promote novel response forms, a demonstration that variability of verbal behavior can be brought under general stimulus control may have conceptual value. We are not aware of any procedures that have that have demonstrated discriminated variability in verbal behavior. Therefore, the effects of a discrimination training procedure on the response variability of verbal behavior in children with autism is unknown.

Finally, a procedure that evaluates the effects of a discrimination training procedure on verbal behavior (in this case, varied manding) may provide helpful conceptual and procedural information to the study of verbal behavior. Skinner (1957) argued that "the listener, as an essential part of the situation in which verbal behavior is observed, is... a discriminative stimulus." Skinner continues to make his case for how different audience members control different subsets of verbal behavior. An understanding of audience control would provide insight on how speaker behavior can come under discriminative control of different cultural audience (see Skinner, 1981, for an analysis of culture as a controlling variable). An understanding of audience control may also provide insight on how children with autism respond differently to various members of the same cultural audience. A starting point for this examination would be to establish two different types of verbal behavior (e.g., variable and repetitive responding) 
in the presence of two different visual stimuli (e.g., a green and red placemat). The placemats would approximate different verbal audiences because they will be associated with different histories of reinforcement for different types of verbal behavior (e.g., varied or repetitive language). Therefore, a study that examines discriminated variability may provide evidence and/or understanding of Skinner's analysis of complex audience control.

Research questions

1) What are the effects of a discrimination training procedure on mand variability and mand repetition, when visual scripts are present, in preschoolers with autism?

2) What are the effects of a discrimination training procedure on mand variability and mand repetition, when visual scripts are absent, in preschoolers with autism?

3) What are the effects of a discrimination training procedure on mand variability and mand repetition, when visual scripts are absent and all responses are reinforced, in preschoolers with autism?

4) What are the effects of a discrimination training procedure on the generalization of mand variability and mand repetition to a new environment, when visual scripts are absent, in preschoolers with autism.

5) What are the effects of a discrimination training procedure on the maintenence of mand variability and mand repetition, when visual scripts are absent, in preschoolers with autism. 
6) What are the effects of the discrimination training procedure on the emission of novel mands in preschoolers with autism? 
CHAPTER III

\section{METHOD}

\section{Participants}

We recruited three preschool-aged participants with autism from a private oncampus university preschool. All participants had the ability to engage in three to five word vocalizations and had a history of edible items functioning as reinforcers. Also, all participants only engaged in one different mand frame, under baseline conditions, prior to the beginning of the study. Kade was an exception to this rule. However, he was included in the study with different experimental arrangements (see below).

\section{Kent}

Kent was a five year old Caucasian male from the United States, and English is the primary language in his home. He was diagnosed with autism by an outside agency. He consistently engaged in the mand frame "I want " prior to the beginning of the study, and he reliably engaged in three to five word sentences. Kent also had basic sightword reading skills, but did not demonstrate any reading comprehension skills.

\section{Kade}

Kade was a five-year-old Caucasian male from the United States, and English is the primary language in his home. He was diagnosed with autism by an outside agency. Prior to the beginning of the study, he reliably engaged in the mand frame "I want . Kade also engaged in basic sight-word reading skills, and demonstrated limited reading comprehension skills. 


\section{Gus}

Gus was a four-year-old Caucasian male from the United States, and English is the primary language spoken in his home. Prior to the beginning of the study, he reliably engaged in the mand frame "I want ___ " and one instance he engaged in the mand frame "Can I have ___. Gus engaged in other three to five word phrases, and demonstrated basic sight-word reading skills. However, Gus demonstrated limited reading comprehension skills.

\section{Setting}

We conducted all sessions in a small research cubical at the participant's preschool or at a horseshoe snack table with other children present. All sessions were 5 min in length, Research assistants conducted two to six sessions each day. The USU Institutional Review Board certified all research participants, and we trained each research assistant to conduct each experimental session with $100 \%$ accuracy before they were able to conduct research sessions.

\section{Materials}

We conducted research sessions at a small table with two chairs. Researchers had data collection materials (e.g., pencil and paper) available, along with a timer and a video camera to record each session. Generalization sessions were conducted in the participant's regular snack environment (e.g., a small horseshoe table with other children with autism present). 
During each session, three snack items were available and placed in front of the participant. During discrimination training and test conditions, we placed a green $\left(\mathrm{S}^{\mathrm{V}}\right)$ or red $\left(\mathrm{S}^{\mathrm{NV}}\right)$ placemat in front of each participant. During script training conditions, we placed four (Kent, and Gus) or five (Kade) scripted mand frames in front of each participant. These scripted mand frames represented the participant's default mand frame (i.e., the mand frame they reliably engage in prior to the study) and three or four new mand frames. See Table 3 for a list of each participant's default and scripted mand frames. Scripts consisted of mand frames printed in black 18-point Times New Roman font on white card stock and they were placed at the bottom of the placemat, equa-distant from each other (see Figure 1)

Table 2

The Default and New Scripted Frames for Each Participant

\section{Participant}

Kent

Gus

Kade

\section{Default Mand Frame(s)}

"I want

"

"I want

"I want "Can I have

\section{Scripted Mand Frames}

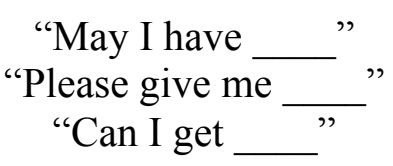

"May I have "Please give me "Can I get

"May I have "Please give me "Can I get "I'd like

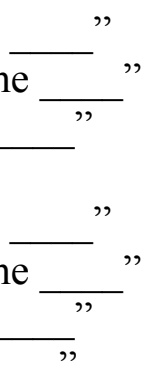


Response Definition and Measurement

\section{Measuring Mand Frames and Variability}

We defined a mand frame as any instance where the participant engaged in a vocal response that included a subject, verb, and noun that corresponded to an available edible item (e.g., "May I have a chip?”). For all response definitions, in order for mand frames to be considered as different from one another, they differed by more than the researcher's name, nouns that correspond to available edible items, rearranging the word order, specifying a number or color of an edible, or adding or deleting "please." For each research session, we recorded the total number of different scripted mands, novel mands, and the total number of mands.

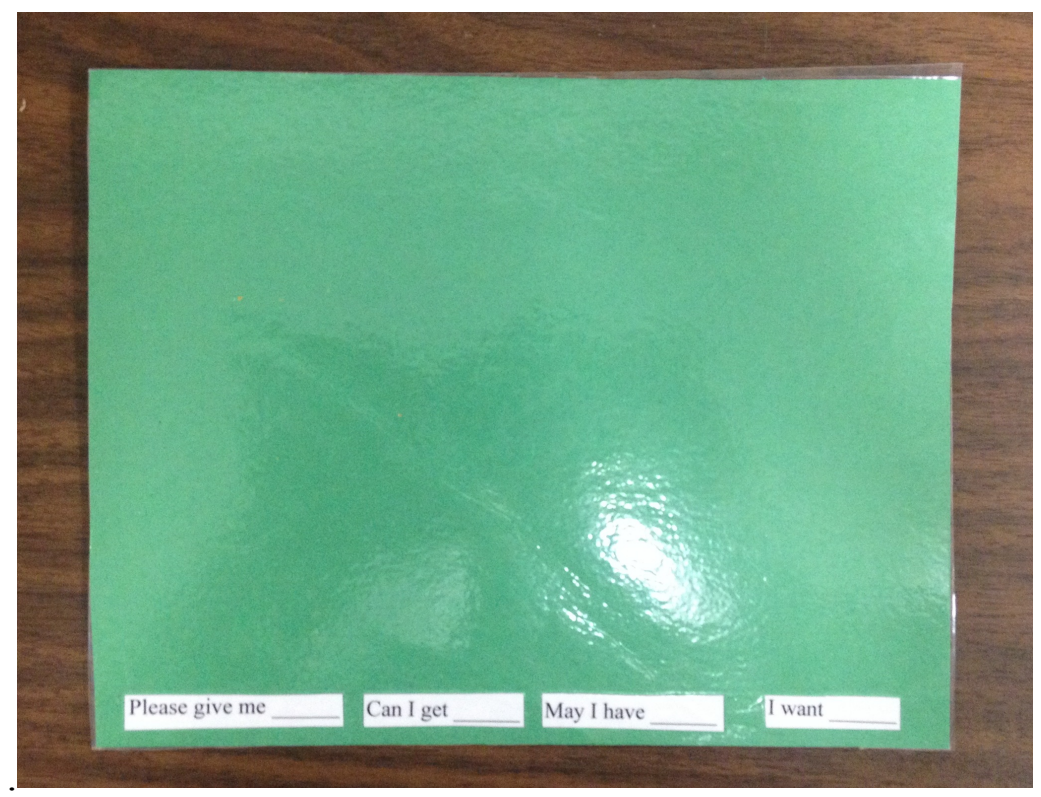

Figure 1. An example of a placemat with four written scripts. 
We defined a scripted mand frame as any instance when the participant engaged in a vocal response that had point to point correspondence with a specific script. Scripted mand frames counted as such regardless of whether or not the script was available to the participant. For example, if a participant engaged in the scripted mand frame "I want a chip" after we faded the "I want___ " script, "I want___, would count as a scripted mand frame. We defined a novel mand frame as any mand other than scripted or default mand frame that occurred in a session. We defined the total number of different mand frames as the number of different mand frames that occurred within each session. We defined the total number of mand frames as the number of mand frames that occurred within each session. For example, if during a session the participant engaged in three scripted mand frames two times each, the total number of mand frames for that session would be six. If the response was prompted, it was also counted in the total mand frames per session. We also tracked the number and types of prompts that occurred each session. Specifically, we tracked whether or not each prompted response occurred after a physical or vocal prompt.

Research assistants transcribed all mand frames using a paper data sheet and pencil. At the end of each session, the research assistant recorded the total number of different scripted mand frames, different novel mand frames and the total number of mand frames.

\section{Measuring Stimulus Discrimination}

In order to determine if the red and green placemat were controlling participant responding, when the error correction and the written scripts were removed, we measured 
the percentage of correct responses in the presence of the green and red placemat. This measure captured whether or not each response met the specific schedule requirements that were associated with each placemat.

Second, we measured the cumulative number of responses that occurred within each session. This measure is useful for visually analyzing the nature of variability that occurred when error correction and scripts were not present. The steeper the slope, the more frequently that response was emitted than other mands.

For Gus, during the Test Vary condition, we measured the number of responses that occurred before an error. This measure was useful in providing information about whether or not Gus's responding was under the control of the green placemat.

\section{Reliability and Treatment Integrity Measures}

Research assistants scored interobserver agreement (IOA) for at least $30 \%$ of the sessions in each condition for all participants. We collected IOA by separately counting the total number of agreements for each mand frame that occurred during the session. We defined agreements as each instance where the primary data collector's transcription had point to point correspondence with the IOA collector's transcription. Then, we divided the total number of agreements by the total number of agreements plus disagreements for each measure, yielding the IOA score for each measure.

Research assistants also scored measures of treatment integrity for at least $30 \%$ of each condition for each participant (see the Appendix). We calculated the total number of correctly implemented components and divided it by the total number of components. Then, we multiplied it by $100 \%$ in order to obtain the treatment integrity score. 
Treatment integrity components included whether or not: (a) ten edible items were presented in the MSWO, (b) three edible items were identified in the MSWO, (c) the researcher said, "It's time for snack" to start the research session, (d) the timer was set to 5-min, (e) the correct placemat was put on the table, (f) the correct colored square was placed on the door of the research room, (g) the researcher started the timer after saying, "it's time for snack," (h) the researcher stopped the session after 5 min elapsed, (i) responses that met reinforcement criteria were reinforced throughout the entire session, (j) responses that did not meet reinforcement criteria were ignored throughout the session, (k) prompts were provided if no responding occurred after 150s, (l) prompts were provided in the correct sequence throughout the session, (m) the participant was seated across the table from the research assistant, (n) prompts were only provided from behind the participant, and (o) the correct prompt sequence data sheet was used.

\section{Script Pre-Training}

Prior to the beginning of the study, we assessed each participant's ability to respond to scripts. We did this by teaching each participant to respond to each individual word for each script by presenting each word on a flashcard with the vocal instruction "read." If the participant engaged in the correct response (i.e., vocally emitted the word on the card) within $5 \mathrm{~s}$, it was counted as a correct independent response. If the participant responded incorrectly, or did not respond within $5 \mathrm{~s}$, the research assistant said "try again" and marked the response as incorrect. The research assistant then represented the card with the vocal instruction "read" and immediately provided a vocal

prompt. If the participant responded correctly to the vocal prompt (i.e., their vocal 
response matched the word on the card), the research assistant said, "good job." If the participant responded incorrectly to the prompt, or did not respond within $5 \mathrm{~s}$, the research assistant proceeded with the same prompting strategy until the participant responded correctly. In all cases, once the participant responded correctly to the prompt, they would be given another opportunity to respond independently.

Each word was mastered once the participant engaged in four out of five independent correct responses (i.e., 80\% accuracy) for two sessions. Following mastery of each word, we verified each participant's ability to respond to script following and fading. To do this, we taught each participant to respond to one script that is unrelated to the study. Then, when the participant responded to each script independently for 4 out of 5 trials $(80 \%)$ across two sessions, we cut off the end of that script, until the script is faded to the first word only. For example, the initial script was "I like to ski," the first fading step the student encountered was the script "I like to __, , then "I like ___ _, and finally "I

\section{Experimental Design}

In order to isolate the effects of the independent variables on the dependent variables, we used a non-concurrent multiple baseline across participants design. A multiple baseline design allowed us to compare responding across individual participants in order to rule out threats to internal validity (e.g., history). In conditions that are designed to test stimulus control, we used a multielement design, because it allowed us to rapidly alternate between Vary and No-Vary conditions. Each phase is described in detail below. 


\section{Experimental Procedures and Conditions}

\section{Preference Assessment}

In order to identify edible items that may function as reinforcers, we interviewed parents and staff who were familiar with the research participants. From these interviews, we identified 10 edible items to use during research sessions. Using these 10 items, the research assistant conducted a brief Multiple Stimulus Without Replacement (MSWO) preference assessment (Carr, Nicholson, \& Higbee, 2000) before the beginning of each experimental session. Specifically, the researcher placed all 10 food items in front of the participant. The research assistant said "take the one you want", and the participant had $5 \mathrm{~s}$ to select a food item. Then, that specific food item was removed from the array, and the remaining nine food items were represented. This occurred until the research assistant identified three food items. The purpose of this assessment was to identify the top three items for the student to request during the upcoming experimental session. Given that our research question relied on independent student requests for preferred items, this procedure was necessary in order to account for changes of participant preference between research sessions.

\section{Baseline}

The purpose of this phase was to measure responding prior to the participant's exposure to the intervention. All complete mand frames were reinforced, and a white placemat was placed directly in front of the participant. For this and all subsequent conditions, the participant sat across the table from the researcher, and a second research assistant stood behind the participant. 


\section{Baseline Generalization Probe}

The purpose of this phase was to measure responding during the participant's typical snack environment when other peers were present. During this condition, the participant sat at their regularly scheduled snack group for 5 min with at least two peers with autism present. All complete mand frames were reinforced, and the participant's regular placemat (i.e., the placemat they used at their early-intervention preschool) was present.

\section{Baseline Vary Probe}

The purpose of this phase was to test if the green placemat controlled participant responding prior to implementing the intervention. The participant's placemat (indicating the Vary condition) was placed directly in front of him. Each complete mand frame was reinforced. Incomplete mand frames were not reinforced.

\section{Baseline No Vary Probe}

The purpose of this phase was to test if the red placemat controlled participant responding prior to implementing the intervention. The participant's placemat (indicating the No Vary condition) was placed directly in front of him. Each complete mand frame was reinforced. Incomplete mand frames were not reinforced.

\section{Baseline Extinction of Repetition Probe}

The purpose of this phase was to measure baseline variability when reinforcement was contingent on varied manding. A white placemat was placed directly in front of the participant. In this phase, the first time a participant engaged in a specific mand frame, 
that response was reinforced. All subsequent responses of that specific mand frame did not result in reinforcement for the remainder of the session. For example, if the participant said, "I would like a cookie," that response resulted in reinforcement. Subsequent responses of "I would like ___ _ did not produce reinforcement. However, if the participant engaged in the response "May I have ___," reinforcement was provided, as long as "May I have____ did not previously occur during the session. Kent and Gus were exposed to one session of the baseline extinction of repetition probe, while Kade was exposed to eight sessions in order to measure the stability of his mand frames over an extended length of time.

\section{Discrimination Training, Script Training, and Script Fading (DT)}

The purpose of the Discrimination Training, Script Training, and Script Fading (DT) condition was twofold. The first goal was to establish discriminated responding in Vary and No Vary conditions. The second goal was to establish participant responding in the presence of the scripts and to fade the scripts so they were no longer in the participant's environment.

To evaluate the effects of the discrimination training procedure, we embedded a multi-element design into the reversal design. The multi-element design consisted of rotating between Vary and No Vary training conditions. We ran at least 1 pair (series) of Vary and No Vary conditions each day, and we used a random number generator to determine the condition we ran first.

Each Vary and No Vary session (described below) during the DT condition began with the participant standing outside of the research room. The door to the research room 
was closed. To the right of the door handle, we attached, with Velcro, a colored square that corresponded to the color of the placemat in the relevant phase (i.e, red for No Vary, green for Vary). We physically guided the participant grab the colored square. Then, we opened the door, guided the participant towards the research table, and physically prompted him to place the colored square above the corresponding placemat hanging on the wall. Then, we physically guided the participant to grab the relevant placemat from the wall. Finally physically guided the participant to put the relevant placemat on the table. The purpose of this procedure was to serve as an additional step to ensure that the participant was attending to the color of each placemat.

For both training conditions below, we began by using a 15 -s constant time delay prompting procedure. That is, after researcher said, "Time for snack" the participant had 15-s to engage in a mand frame. If the participant did not engage in a mand frame, the researcher standing behind the participant immediately guided the participant to touch a pre-determined script (see below). If the participant engaged in the correct mand frame (i.e., it met the Lag schedule of reinforcement during the Vary condition or was a default mand frame during the No Vary condition), we provided reinforcement. If the participant did not respond to the prompt within $5 \mathrm{~s}$ or engaged in an incorrect mand frame (i.e., it did not meet the Lag schedule of reinforcement during the Vary condition or was not the default mand frame during the No Vary condition), we provided a physical prompt and a vocal prompt every $5 \mathrm{~s}$ until the participant engaged in the correct response. Following the consumption of the item, the participant had $15 \mathrm{~s}$ to engage in the next response.

If at any point the participant engaged in a varied response in the No Vary session (red placemat) or did not meet criteria for reinforcement during the Vary session (green 
placemat), we provided three consecutive prompts in a predetermined order (see below). The purpose of providing three consecutive prompts was to provide prolonged exposure of varied responding in the presence of the green placemat, and repetitive responding in the presence of the red placemat.

We faded the scripts from back to front, one word at a time. For example, "I would like ___ _ _ "I would ___ _ I _ _ _ _ E E E _ Ech fading step occurred once the participant independently followed all scripts, or emits the full scripted mand frame with no vocal prompts, during $80 \%$ of opportunities across two sessions.

No Vary training condition. The purpose of this condition was to teach the participant to only engage in their default mand frame the presence of the red placemat. It was also designed to serve as a control condition for the vary sessions. The red placemat had four (Kent and Gus) or five (Kade) scripted mand frames attached to it. The red placemat was placed directly in front of the participant. Though reinforcement was only contingent on using the default mand frame, four or five scripts were available in order to hold the number of scripts constant across Vary and No Vary training conditions and establish the color of the placemat as the stimulus controlling the response pattern. If the participant engaged in a mand frame other than their default mand frame, we provided three consecutive prompts for them to engage in their default mand frame. Though Kade had two default mand frames (i.e., "I want___ and "Can I have ___"), we always physically prompted him to engage in the response "I want ___ ").

Vary training condition. The purpose of this condition was to teach the participant to engage in varied responding the presence of the green placemat. The green placemat had four or five scripted mand frames attached to it, and it was placed directly 
in front of the participant. A Lag 2 (Kent and Gus) or Lag 3 (Kade) schedule of reinforcement was in place. That is, in order for the participant to earn access to reinforcement, the current mand frame had to differ from the previous two (Lag 2) or three (Lag 3) mand frames.

If at any point the participant did not meet the Lag schedule requirement, or did not engage in a response after $15 \mathrm{~s}$ elapsed, we used an error correction procedure to prompt a series of three different mand frames. Before the beginning of each session, we used a random number generator to determine which of the four prompt sequences we used for that phase. We used a predetermined prompt sequence in order to eliminate experimenter bias during the prompting procedures. At all times the error correction sequence met reinforcement schedule requirements. Consider an example where, in the vary condition, the participant engaged in response $\mathrm{A}$, then response $\mathrm{B}$, then response $\mathrm{B}$ (a repetitive response). If this sequence occurred, we prompted response $\mathrm{C}$ (which earned access to reinforcement), response A (which earned access to reinforcement), and response D (which earned access to reinforcement). At this point, the participant was given the opportunity to respond independently. Both response options $\mathrm{B}$ and $\mathrm{C}$ would produce reinforcement under the Lag 2 schedule, for example, and if the participant engaged in response options A or D, we introduced further error correction.

The purpose of using a Lag 2 (and Lag 3 for Kade) schedule of reinforcement was to increase the probability that the participant would engage in a correct independent response after the error correction procedure. With a Lag 2 (Lag 3 for Kade) schedule of reinforcement, two response options were available to the participant following error correction (see the example above). In other words, the participant would have a $50 \%$ 
chance ( $40 \%$ for Kade) of engaging in the correct response. With a Lag 3 schedule of reinforcement for Kent and Gus, or a Lag 4 schedule of reinforcement for Kade, following the error correction procedure, the participants would have a $25 \%$ chance $(20 \%$ for Kade) of independently earning access to reinforcement, since only 1 response option would be available. Therefore, we felt that the Lag 2 schedule of reinforcement for Kent and Gus, and a Lag 3 schedule of reinforcement for Kade was an appropriate schedule of reinforcement to produce independent response variability.

Delayed Prompting (Kent only). During script training, we observed that Kent appeared to have become reliant on adult vocal prompting. To manage this, after the $20^{\text {th }}$ script training session, we modified our prompting procedures. Specifically, we provided three physical prompts (without accompanying vocal prompts), separated by $5 \mathrm{~s}$, if Kent engaged in an incorrect response or met criteria for prompting. If Kent did not engage in the correct response after three consecutive physical prompts, we provided a fourth physical prompt and an accompanying vocal prompt. The physical and vocal prompts simultaneously occurred until Kent engaged in the target prompted response.

Script booster sessions (Kent only). During script training, Kent appeared to have trouble acquiring the scripted mands "Can I have ___ " and "Please give me ___". As a result, we conducted six booster sessions, independent of the experimental procedures, to help establish these two mand frames. Each booster session consisted of 10 trials for each script (for a total of 20 trials per session). Specifically, Kent sat at a table across from a research assistant. A second research assistant stood behind Kent. The research assistant presented the script to Kent. If Kent read the script within $5 \mathrm{~s}$, praise and a small edible item was provided. It was not necessary for Kent to fill in the 
blank with the name of an edible item. If Kent did not read the script within $5 \mathrm{~s}$, or engaged in a response that did not have one-to-one correspondence with the script, the research assistant removed the script. Then, the research assistant represented the script, and the researcher standing behind Kent read the script while simultaneously physically guiding Kent to touch each word. Once Kent read the script with the help of the prompt, the research assistant presented the script and allowed Kent an opportunity to respond independently. The booster session was discontinued once Kent engaged in each script at $80 \%$ accuracy, without researcher prompting, for one session.

Contingency exposure (Gus only). After the $18^{\text {th }}$ script training session, Gus was engaging in varied responding during the No Vary condition. We hypothesized that Gus's responding was under the control of researcher prompting and not the relevant visual cues. To mitigate this, we introduced a Contingency Exposure condition where, at the beginning of each session, we physically prompted three responses before Gus had a chance to engage in an independent response. We hypothesized that this procedure would bring Gus's behavior under stimulus control because it allowed Gus to experience the contingencies associated with each placemat before he made an error.

Alternating placemats (APM; Gus only). Following the Contingency Exposure condition, Gus demonstrated response variability during the No Vary phase. To further attempt to establish appropriate stimulus control, we introduced a condition where we alternated between Vary and No Vary placemats within each session. Since the Contingency Exposure condition was not successful, we hypothesized that a more intensive intervention may be successful. This intervention, in particular, allowed Gus to experience the contingencies associated with each placemat four times across the 
experimental condition, instead of one time across the initial DT conditions. We began each session with no placemat on the table. After the researcher said, "It's time for snack" we placed the Vary or No Vary placemat in front of Gus and provided physical prompts in the correct sequence (repetitive for No Vary, and varied for Vary) for $75 \mathrm{~s}$. After 75-s, we removed the placemat and replaced it with the other placemat, and then continued to prompt the correct sequence for another $75 \mathrm{~s}$. This continued until $5 \mathrm{~min}$ elapsed. During the Alternating Placemats (APM) condition, all responses were physically prompted in an attempt to maximize exposure to the relevant visual cues and corresponding contingencies and to minimize the probability of Gus making an error.

\section{Script Fading and Discrimination Test Conditions}

To test the effects of the script fading and discriminating training procedures, we used use a multi-element design. Specifically, we rotated between the Vary and No Vary

Test Vary condition. The purpose of this condition was to evaluate participant responding in the presence of the green placemat without scripts and researcher prompting. During this condition, we placed the green placemat in front of the student and said "It's time for snack." Scripts were not available. A Lag 2 (Kent and Gus) or Lag 3 (Kade only) schedule of reinforcement was in place. During this condition, no prompts or error correction was provided.

Test No Vary condition. The purpose of this condition was to evaluate participant responding in the presence of the red placemat without scripts and researcher prompting. During this condition, we placed the red placemat in front of the participant and said "It's time for snack." Scripts were not available. Reinforcement was provided 
only when the participant engaged in their default mand frame. All other mand frames or incomplete mand frames did not produce reinforcement. During this condition, no prompts were provided.

\section{Placemats Only}

To test the effects of antecedent stimuli (i.e., the red and green placemats) on participant responding in the absence of different contingencies, we used a multi-element design that rotated between the following two conditions.

Placemats Only Vary. The purpose of this condition was to evaluate participant responding in the presence of the green placemat without scripts, researcher prompting, or the Lag schedule of reinforcement. During this condition, the green placemat was present and reinforcement was provided for every mand frame, regardless of whether or not it was varied. All incomplete mand frames were not reinforced. During this condition, no prompts were provided.

Placemats Only No Vary. The purpose of this condition was to evaluate participant responding in the presence of the red placemat without scripts, researcher prompting, or the Lag schedule of reinforcement. During this condition, the red placemat was present and reinforcement was provided for every mand frame, regardless of whether or not it was repetitive. All incomplete mand frames were not reinforced. During this condition, no prompts were provided.

\section{Generalization and Maintenance}

We conducted the following sessions to test the effects of the discrimination training procedure on the generalization and maintenance of the DT condition. 
Generalization Vary. The purpose of this condition was to evaluate the effects of the training procedure in a natural environment. This condition took place during the participant's regularly scheduled snack time, and otherwise resembled that of the Placemats Only Vary condition. For Gus, this condition resembled that of the Test Vary condition with both the placemat and its associated schedule of reinforcement in effect.

Generalization No Vary. The purpose of this condition was to evaluate the effects of the training procedure in a natural environment. This condition took place during the participant's regularly scheduled snack time, and otherwise resembled that of the Placemats Only No Vary condition. For Gus, this condition resembled that of the Test No Vary condition.

Follow Up Vary. In order to evaluate the potential long term effects of the training procedures, this condition took place 2 weeks after the final research session. This condition resembled that of the Placemats Only Vary condition. For Gus, this condition resembled that of the Test Vary condition.

Follow Up No Vary. In order to evaluate the potential long term effects of the training procedures, this condition took place 2 weeks after the final research session. This condition resembled that of the Placemats Only No Vary condition. For Gus, this condition resembled that of the Test No Vary condition. 
CHAPTER IV

RESULTS

\section{Pre-Experiment Script Training and Fading}

Each participant finished the pre-experiment script training and fading

procedures. Sessions to mastery ranged from 2 to 5 for Kade, 3 to 28 for Kent, and 2 to 5 for Gus. See Table 4 for a list of trials to mastery for each target for each participant.

\section{Treatment Integrity}

Treatment integrity was collected for at least $75 \%$ of each condition for each participant. Treatment integrity was collected for $84.7 \%$ of research sessions for

\section{Table 3}

Sessions to Mastery for the Pre-experiment Script Training and Fading Procedures

\begin{tabular}{lccc}
\hline Target & Kade & Kent & Gus \\
\hline "I" & 2 & 3 & 2 \\
"Want" & 2 & 13 & 3 \\
"A" & 2 & 7 & 2 \\
"Please" & 2 & 17 & 2 \\
"Give" & 2 & 20 & 2 \\
"Me" & 2 & 12 & 2 \\
"May" & 2 & 28 & 5 \\
"Have" & 2 & 21 & 2 \\
"Can" & 2 & 22 & 2 \\
"Get" & 2 & 21 & 2 \\
"Id" & 2 & 12 & 2 \\
"Like" & 2 & 5 & 2 \\
"I like to ski" & 5 & 8 & 4 \\
"I like to_" & 3 & 3 & 3 \\
"I like_—" & 2 & 4 & 3 \\
"I ——— — & 2 & 4 & 2 \\
\hline
\end{tabular}


Kade, with an average of $97.57 \%$ (range, $80-100 \%$ ). For Gus, treatment integrity was collected for $77.2 \%$ of research sessions, with an average of $99 \%$ (range, $80-100 \%$ ). Treatment integrity was collected for $82.5 \%$ of research sessions for Kent, with an average of $99.36 \%$ (range, $80-100 \%$ ).

\section{Interobserver Agreement}

IOA was collected for at least $40 \%$ of each condition for each participant. IOA was collected for $48.6 \%$ of Kade's research sessions, with IOA of $100 \%$ for the number of different mand frames per session, and an average IOA of 99.3\% (range, 91.6-100\%) for the total number of mand frames per session. IOA was collected for $54 \%$ of Kent's research sessions, with an average IOA of $97.3 \%$ (range, 66.6-100\%) for the number of different mand frames per session, and an average IOA of $98 \%$ (range, $87.5-100 \%$ ) for the number of different mand frames per session. IOA was collected for $40.59 \%$ of Gus's research sessions, with an IOA of $100 \%$ for the number of different mand frames per session, and an average IOA of $99.27 \%$ (range, $90-100 \%$ ) for the total number of mand frames per session.

\section{Experimental Sessions}

Below, the results for each participant are described for each phase. See Figure 2 for the number of different mand frames for each session. See Figure 3 for the total number of mand frames for each session. 


\section{Baseline}

Kent. When all complete mand frames produced reinforcement, Kent engaged in 1 different mand frame (i.e., "I want ") during each baseline session. The frequency of mand frames ranged from seven to nine mand frames per session.

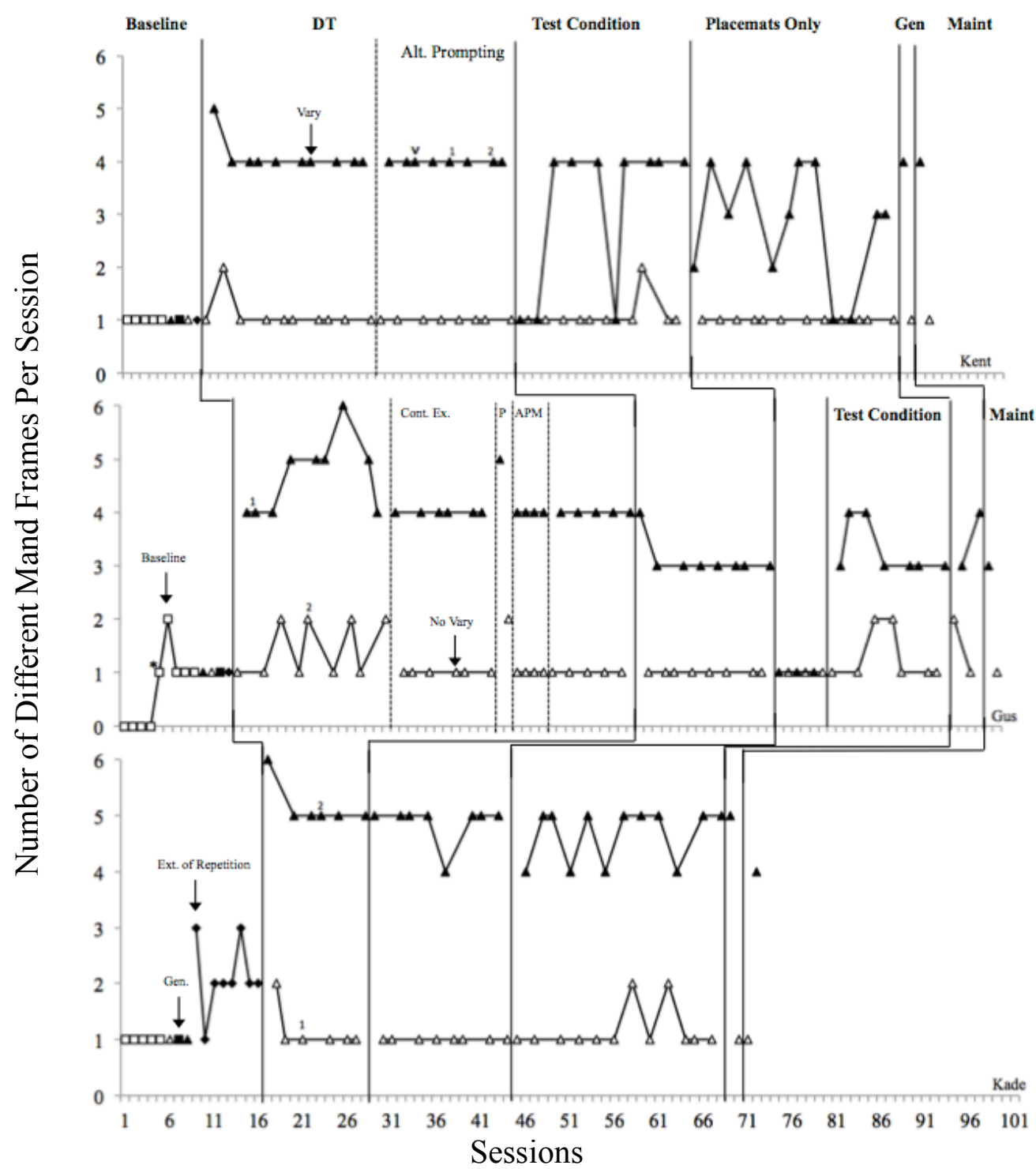

Figure 2. The number of different mand frames per session for Kent, Gus, and Kade. The numbers 1 and 2 depict sessions following the $1^{\text {st }}$ and $2^{\text {nd }}$ script fading step, respectively. * denotes the session after Gus's baseline booster session. ${ }^{\wedge}$ denotes the session after Kent's script training booster sessions. 
He continued to engage in the mand frame "I want ___ across the Vary, Generalization, No Vary, and Extinction of Repetition probes, with a frequency ranging from six to eight mand frames per session. During the Extinction of Repetition probe, he engaged in challenging behaviors in the forms of yelling and flopping to the ground. He also kicked his chair over during the final minute of the session. Because challenging behavior had not been observed during previous conditions, it was hypothesized that the extinction contingencies were at least partially responsible for the occurrence of challenging behaviors.

Gus. During the first four baseline sessions, Gus did not engage in any complete mand frames. His lack of responding was possibly due to a failure in treatment integrity during the first baseline condition, where an incomplete mand frame was unintentionally reinforced. Before the fifth baseline session, a 5-min booster session was conducted. Prior to the beginning of the booster session, the researcher said, "Gus, if you want something, you need to use a full sentence and a big-boy voice." This statement was chosen for two reasons. First, it was a rule his teachers commonly used in his clinical setting. Second, "You need to use a full sentence" described the response requirements of the baseline condition without explicitly encouraging him to engage in a specific mand frame.

Following the 5 min booster session, Gus engaged in one different mand frame during the fifth baseline session (i.e., "I want___"), two different mand frames during the sixth session (i.e., "I want ___ " and "Can I have ___"), and one different mand frame (i.e., "I want ___") during the seventh, eighth, and ninth baseline session. Between the sixth and ninth baseline session, the frequency of complete mand frames 
ranged from 12 to 14 mand frames per session. During the Vary, No Vary,

Generalization, and Extinction of Repetition probes, Gus's engaged in one mand frame (i.e., "I want___") and the frequency of complete mand frames ranged from 6 to 14 for each session.

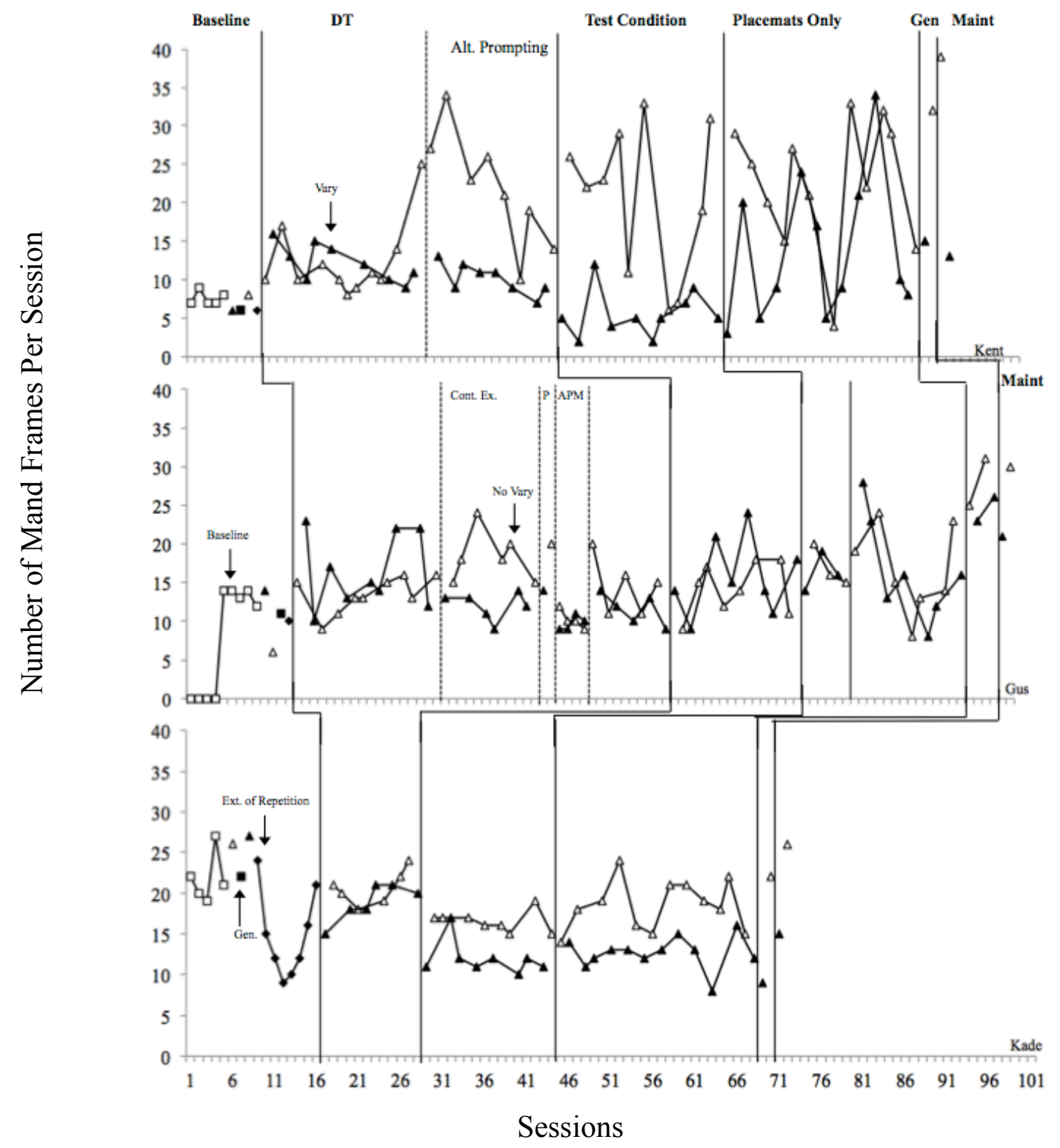

Figure 3. The total number of mand frames per session for Kent, Gus, and Kade. 
Kade. During the Baseline conditions and the Vary, No Vary, and

Generalization probes, Kade engaged in 1 different mand frame (i.e., "I want ") for each session. The frequency of his responses ranged from 19 to 27 responses per session. During the first Extinction of Repetition session, Kade engaged in 3 different mand frames (i.e., "I want ___, "Please may I have ___, and "Can I have ___"). Because of the increased number of different mand frames during this phase compared to previous baseline conditions, we conducted additional Extinction of Repetition sessions. During the second Extinction of Repetition session, Kade engaged in 1 different mand frame ("Can I have___"). For the next three Extinction of Repetition conditions, Kade engaged in 2 different mand frames during each session (i.e., "Can I have ___ and "I want___"). During the sixth Extinction of Repetition condition, Kade engaged in three different mand frames (i.e., "Can I have ___," "Can I have some ___," and "I want "). During the final two Extinction of Repetition sessions, Kade continued to engage in two different mand frames per session (i.e., "Can I have ___ " and "I want __ ”). In summary, Kade reliably engaged in two different mand frames when reinforcement was contingent on variability. The response form "Please may I have ___ only occurred during one session, and therefore we determined it was a weak response in Kade's repertoire. Also, the response form "Can I have some ___ "was a slight variation of Kade's default mand frame "Can I have ___." Because of these factors, and because he reliably engaged in repetitive behavior that we deemed would not be clinically appropriate, we included Kade in the study with additional modifications to his response requirements and script training procedures. That is, we used a Lag 3 schedule of reinforcement (instead of a Lag 2), and we taught Kade five scripts (instead of four). 
During the Extinction of Repetition conditions, the frequency of Kade'0s responses ranged from 9 to 24 responses per session. During the first Extinction of Repetition session, Kade engaged in 24 mand frames. During the following three sessions, he engaged in 15,12 , and 9 responses per session, respectively. During the next four Extinction of Repetition sessions, his responding increased from 10, to 12, to 16, to 21 responses per session, respectively.

Finally, during the Extinction of Repetition condition, Kade engaged responses that were not observed in previous sessions when his responses did not produce reinforcement. Specifically, he became teary-eyed, engaged in quiet self-talk, and often shrugged his shoulders. Though these behaviors were not a primary dependent variable of this study, it is important to note that the Extinction of Repetition phase was likely responsible for the additional responding we observed.

\section{Discrimination Training, Script Training, and Script Fading Condition}

Kent. Kent began the DT Vary condition by engaging in 4 scripted mand frames (i.e., "I want ," "Can I get ," "May I have ," and "Please give me ") and 1 unscripted mand frame (i.e., "Can I have "). Otherwise, he engaged in four scripted mand frames during the rest of the DT Vary conditions. Kent engaged in one scripted mand frame (i.e., "I want ") during the DT No Vary condition, except for the second DT No Vary session, where he engaged in two scripted mand frames ("I want " and "Can I have "). The frequency of Kent's responding ranged from 7 to 16 mand frames across the DT Vary sessions, and 8 to 34 mand frames across the DT No Vary sessions. 
After 20 sessions of the DT condition, Kent was not engaging in independent responding that met criteria for script fading. We hypothesized that Kent had become reliant on adult prompting, so we changed the prompting procedures. Specifically, we provided three physical prompts (instead of one), before providing a vocal prompt. This prompting strategy remained in place for the rest of the script training sessions.

Following the $26^{\text {th }} D T$ session, we conducted a series of booster sessions (see above) to help Kent acquire the scripts "Can I get ___ " and "Please give me ___ ”. Specifically, we conducted nine sessions where we ran 10 trials of scripted mand. For each trial, we presented the script to Kent and allowed $5 \mathrm{~s}$ for him to respond. If he engaged in a correct response (i.e., read the script), we provided praise and a small edible item. If he engaged in an incorrect response, or did not respond, the script was removed. We then represented the script and provided a vocal (i.e., we read each word out loud) and a physical (i.e., the guided Kent to touch each word) prompt. This prompting continued until Kent engaged in a response that matched the vocal prompt. Then, we removed the script and represented it, allowing Kent an opportunity to respond independently.

We discontinued the booster sessions once Kent engaged in an independent scripted response $80 \%$ of the time, across both scripts, for one 10 -trial session. Following the script training booster session, Kent began to correctly read each script on the green and red placemats. As a result, we faded the scripts on the $30^{\text {th }}$ and $34^{\text {th }} D T$ sessions. During all sessions, Kent did not engage in any novel mand frames.

Gus. During the first, second, third, and DT Vary sessions, Gus engaged in four different scripted mand frames per session. During the fourth and sixth DT Vary session, 
Gus engaged in four scripted mand frames, and one novel mand frame (i.e., "May I get ”). During the fifth Vary session, Gus engaged in four scripted mand frames, and 1 unscripted mand frame (i.e., "Can I have ”). During the seventh DT Vary session, Gus engaged in 4 scripted mand frames and 2 novel mand frames (i.e., "Can I have and "May I get___"). During the first nine DT Vary sessions, Gus's frequency of mand frames ranged from 10 to 23 per session. During the first nine DT No Vary sessions of the DT condition, Gus's manding ranged from one to two different mand frames per session. In each case where two different mand frames were observed during the DT No Vary condition, Gus only engaged in a mand frame other than "I want___ " in one instance. After he engaged in a mand frame other than "I want___, we engaged in an error correction procedure and Gus subsequently engaged in "I want___ " for the remainder of each DT No Vary session. This error correction procedure was implemented in order to teach Gus to engage in repetitive manding (i.e., "I want___") in the presence of the red placemat. During the first nine DT No Vary sessions, the frequency of Gus's manding ranged from 9 to 16 mand frames per session. Scripts were faded after the second and fourth series (pair) of DT Vary and No Vary sessions.

Because Gus was engaging in varied responding during the DT No Vary condition, we implemented a Contingency Exposure condition that was similar to the previous script training condition, except that we began each session by prompting the first three responses before Gus had an opportunity to independently respond. During the Contingency Exposure condition, Gus engaged in four different scripted mand frames across all Contingency Exposure Vary condition, and one different scripted mand frame (i.e., "I want___") across all Contingency Exposure No Vary conditions. Gus's 
frequency of mand frames ranged from 15 to 36 mand frames per session during the Contingency Exposure No Vary conditions, and 9 to 14 different mand frames during the Contincy Exposure Vary conditions.

Following the Contingency Exposure condition, we implemented a probe phase that resembled the initial DT condition. During the DT Vary session, Gus engaged in four scripted mand frames and one unscripted mand frame (i.e., "May I get __ ”), for a total of 14 mand frames during that session. During the DT No Vary session, Gus engaged in two different scripted mand frames (i.e., "I want___ " and "Can I get ___"), for a total of 20 mand frames during that session.

Because we observed response variability during the previous DT No Vary session, we concluded that the Contingency Exposure condition did not produce repetition during the No Vary session. Therefore, we implemented an Alternating Placemats condition. During this condition, Gus engaged in four different mand frames during the Alternating Placemats Vary sessions, and 1 different mand frame during the Alternating Placemats No Vary sessions. Gus's frequency of responding ranged from 9 to 11 mand frames during the Alternating Placemats Vary sessions, and 9 to 12 mand frames during the Alternating Placemats No Vary sessions.

Following four sessions of the Alternating Placemats condition, we implemented a condition that resembled that of the initial DT condition. During this condition, Gus engaged in four different scripted mand frames during the five DT Vary sessions, and one different mand frame during the five DT No Vary sessions. During the DT Vary sessions, the frequency of Gus's mand frames ranged from 9 to 14 mand frames per session. During the DT No Vary sessions, the frequency of Gus's mand frames ranged from 11 to 
20 mand frames per session. Because Gus reliably engaged in 1 different mand frame during DT No Vary conditions that followed the Alternating Placemats condition, we concluded that the Alternating Placemats condition had been successful in establishing repetitive responding during the DT No Vary condition. As a result, we withdrew the scripts and continued to the next experimental condition.

Kade. During the first DT Vary session, Kade engaged in five scripted mand frames and 1 novel mand frame (i.e., "Please give me some "). Otherwise, he engaged in the five scripted mand frames for the remainder of the DT Vary conditions. During the first script training DT No Vary condition, Kade engaged in two different mand frames (i.e., "Can I have ___ and "I want___"). Otherwise, for the remainder of the DT No Vary sessions, he engaged in only one mand frame (i.e., "I want ") per session. We faded the scripts after the second and fourth series of DT Vary and No Vary conditions. During the DT Vary conditions, the frequency of mand frames ranged from 17 to 21 mand frames per session. During the DT No Vary conditions, the frequency of complete mand frames ranged from 18 to 27 mand frames per session.

\section{Test Vary and No Vary Condition}

Kent. During the first two sessions of the Test Vary sessions where responses were reinforced on a Lag 2 schedule of reinforcement, Kent engaged in 1 different mand frame "I want ." Then, he engaged in four scripted mand frames (i.e., "I want __, "May I have ___ _, "Can I get ___ _ and "Please give me ___ _) across all but the fifth Test Vary session. During the fifth Test Vary session, he engaged in one different mand frame (i.e., "I want "). The frequency of Kent's responding ranged 
from 2 to 11 responses per Test Vary session. Kent did not engage in any novel mand frames.

Kent engaged in one different mand frame (i.e., "I want ") across all but one Test No Vary session. During the eigth Test No Vary session, he engaged in the mand frame "Please give me ___ one time. The frequency of Kent's responding ranged from 7 to 33 responses per session during the Test No Vary condition.

We also measured the percentage of responses that met schedule requirements throughout the Test Vary and No Vary conditions. A correct response was scored if it met the Lag schedule of reinforcement (Test Vary condition) or was a default mand frame (i.e., "I want___ "; Test No Vary condition). Responses that did not meet the Lag schedule (Test Vary) or were not a default mand (Test No Vary) were counted as incorrect. This secondary dependent variable was used to provide insight on the response variability or repetition that occurred throughout each session. During the first three Test Vary sessions, Kent's percentage of correct responses was $20 \%, 50 \%$, and $83.33 \%$, respectively (see Figure 4). On the fourth Test Vary session, 100\% of Kent's responses met the Lag 2 schedule of reinforcement. Correct responding decreased to $80 \%$ and $50 \%$, respectively, for the next two sessions, then rose back to $100 \%$ for the following four Test Vary sessions.

During the Test No Vary sessions, Kent engaged in 100\% correct responding during all but the eighth session. In this session, he engaged in the mand frame "Please give me __ " one time. Otherwise, he continued to engage in the mand frame "I want " throughout the remainder of the session. It should be noted that when Kent engaged in the mand frame "Please give me ___ it was not reinforced, as the purpose 
of this condition was to establish and maintain repetitive responding in the presence of the red placemat.

Finally, we also measured the cumulative number of each mand frame that occurred across each Test Vary session (see Figure 5). The cumulative record graph provides useful analysis for measuring how responding occurred across responses. The steeper the slope, the more often that response was emitted, relative to other responses. Aside from the first 8 responses of "I want ___," the slopes for each mand frame are relatively similar across the remainder of responses observed across the Test Vary sessions. The data paths for "Please give me ___ " and "May I have ___ frequently overlapped, and “Can I get ___ " was often within 1 response of overlapping with "Please give me ___ and "May I have ___. . The reason why the "I want ___ slope

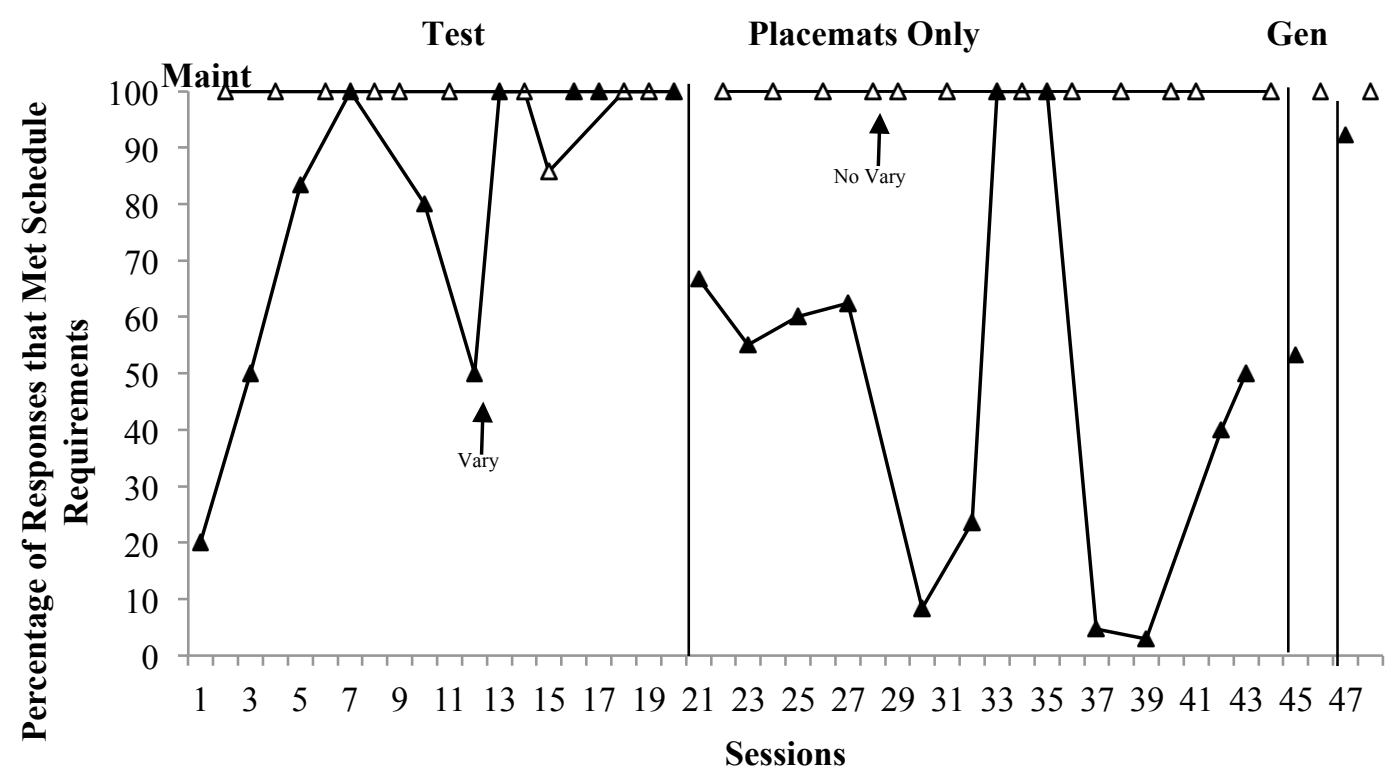

Figure 4. The percentage of Kent's responses that met schedule requirements once the scripts were removed. 
is initially steeper than other data paths is because Kent did not engage in mand variability during the Test Vary condition until the third session. Overall, this analysis suggests that, when Kent did vary his mand frames, he engaged in each mand frame a similar number of times.

Gus. With the scripts removed and a Lag 2 schedule of reinforcement still in place, Gus engaged in three to four different mand frames, per session, across the Test Vary condition. When Gus engaged in four different mand frames, those mand frames were three scripted mand frames (i.e., "I want ___,, "May I have ___," and "Can I get ") and 1 novel mand frame (i.e., "Can I have "). The fourth scripted mand frame, "Please

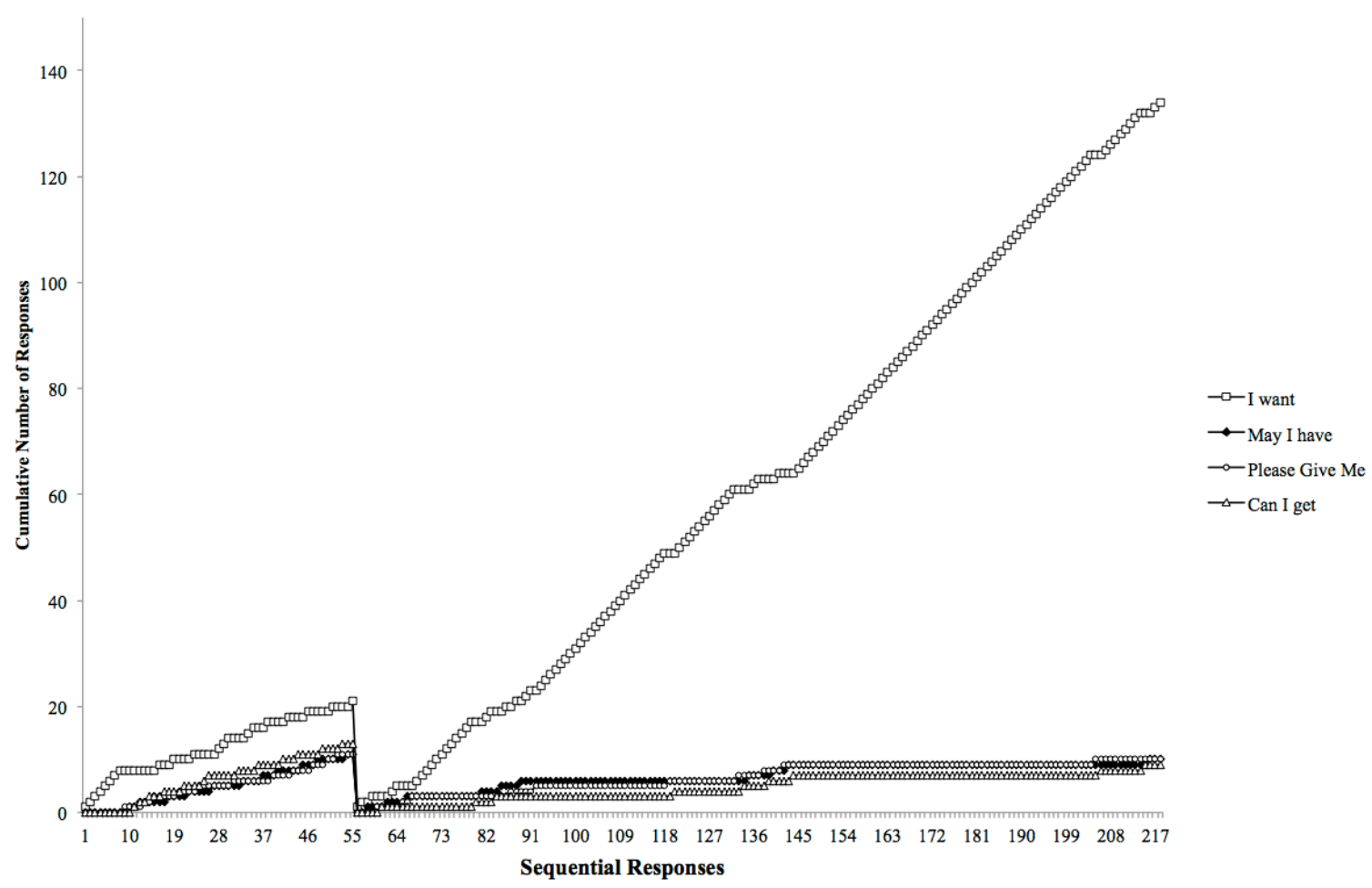

Figure 5. Kent's cumulative number of responses of each mand frame across the Test Vary condition and the Placemats Only Vary condition. 
give me " was not observed. The frequency of Gus's mand frames ranged from 9 to 24 mand frames per session. During the Test No Vary condition, Gus engaged in his default mand frame (i.e., "I want ") across all sessions. The frequency of Gus's mand frames ranged from 9 to 18 mand frames per session.

The percentage of responses that met Lag schedule requirements ranged from $42.8 \%$ to $88.8 \%$ across the first eight Test_Vary sessions (see Figure 6). Following the Placemats Only condition, Gus's correct responding ranged from $52.1 \%$ to $100 \%$ across the next seven Test Vary sessions. Gus engaged in responding at least $80 \%$ accuracy during 10 of the 15 Test No Vary sessions.

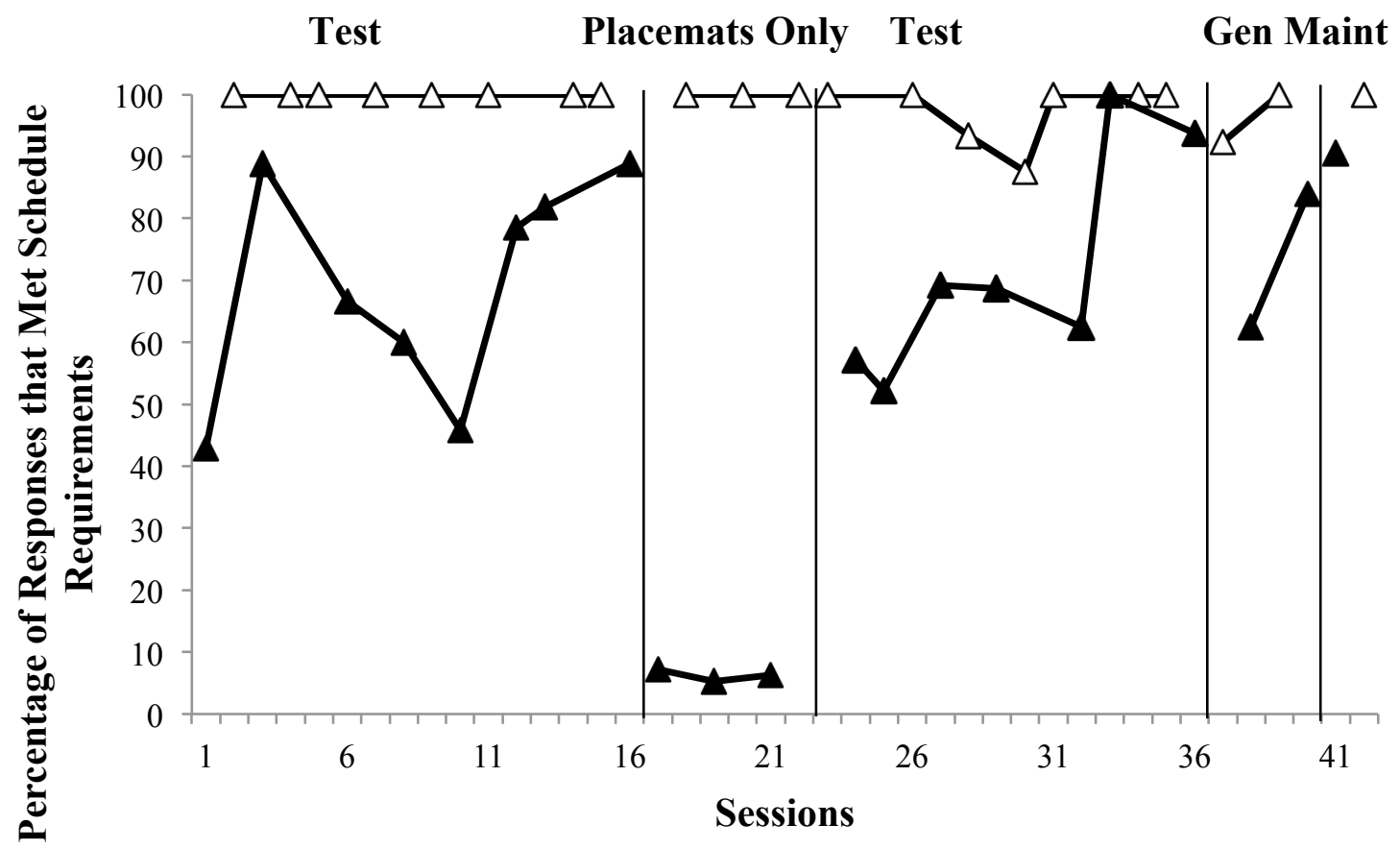

Figure 6. The percentage of Gus's responses that met schedule requirements once the scripts were removed. 
Gus's accuracy across the first eight Test No Vary conditions was $100 \%$.

Following the re-implementation of the Test No Vary condition, Gus's accuracy remained at $100 \%$ across five of 7 sessions. During the two Test No Vary sessions where Gus engaged in varied responding, he engaged in correct responding $93.3 \%$ and $87.5 \%$ of the time, respectively.

During the Test Vary sessions, Gus engaged in the scripted mand frame "I want " more frequently than the scripted mand frames "Can I get ___ " and "May I have ," and the unscripted mand frame "Can I have ___ " (see Figure 7). Given the noticeable difference between the slopes of each mand frame, Gus did not engage in each mand frame a similar number of times.

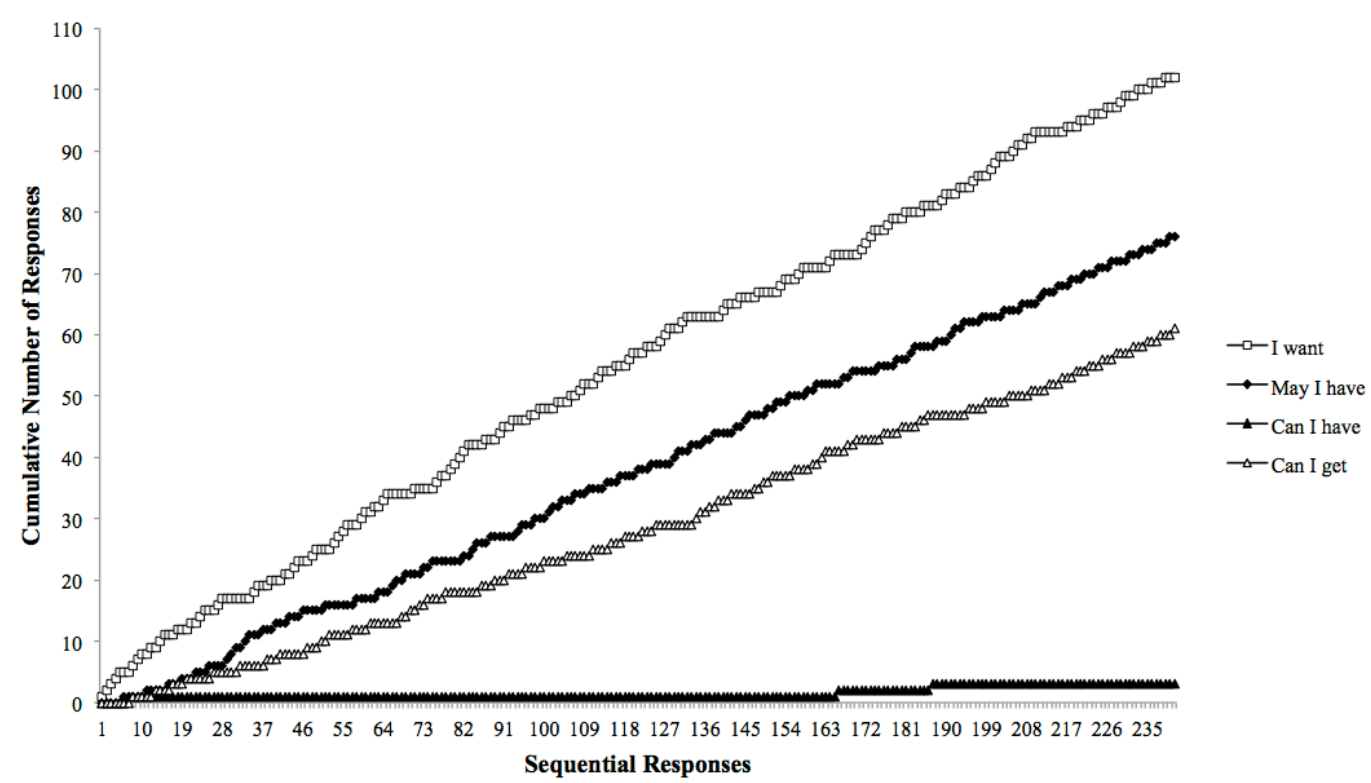

Figure 7. Gus's cumulative number of responses of each mand frame across the Test Vary Condition. 
Kade. During the Test Vary condition where responses were reinforced on a Lag 3 schedule of reinforcement, Kade engaged in five different scripted mand frames across all but one session. During the fifth Test Vary condition, Kade engaged in four scripted mand frames, omitting the scripted mand "May I have ___." During the Test No Vary conditions, Kade reliably engaged in only one different mand frame across eight sessions. During the Test Vary condition, the frequency of mand frames ranged from 10 to 17 mand frames per session. During the Test No Vary condition, the frequency of mand frames ranged from 15 to 19 mand frames per session. Kade did not engage in any novel mand frames.

During the Test Vary condition, the percentage of Kade's responses that met the Lag 3 schedule of reinforcement ranged from $63.6 \%$ to $100 \%$ across eight sessions (see Figure 8). In the last three sessions of the Test Vary condition, Kade's engaged in 100\%, 100\%, and 90.9\% correct responding, respectively. During the Test No Vary condition, $100 \%$ of Kade's responses were his default mand frame (i.e., "I want ___"). Across the Test Vary condition, Kade engaged in his default mand frame "I want __ " more frequently than the other scripted frames (see Figure 9). The remaining four scripted mand frames (i.e., "Can I have ___," "May I have ___," "Please give me ," and "I'd like __ _ had similar slopes across the first 35 responses. Then, "Can I have ___ occurred more frequently than "Please give me ___," "I'd like ___," and "May I have __ " for the remainder of the Test Vary condition. Both "Please give me _ the Test Vary condition. "May I have __ " occurred the least frequently of all the 
scripted mand frames. During Test Vary sessions where Kade engaged in four of five scripted mand frames, he reliably omitted the "May I have __ " mand frame.

\section{Placemats Only}

Kent. The number of different mand frames during the Placemats Only Vary condition, where all complete mand frames were reinforced, was variable, ranging from one to four different mand frames per session (see Figure 2). During the Placemats Only No Vary condition, Kent continued to only engage in the mand frame "I want . The frequency of Kent's responding through the Placemats Only Vary condition was also variable, ranging from 3 to 34 mand frames per session.

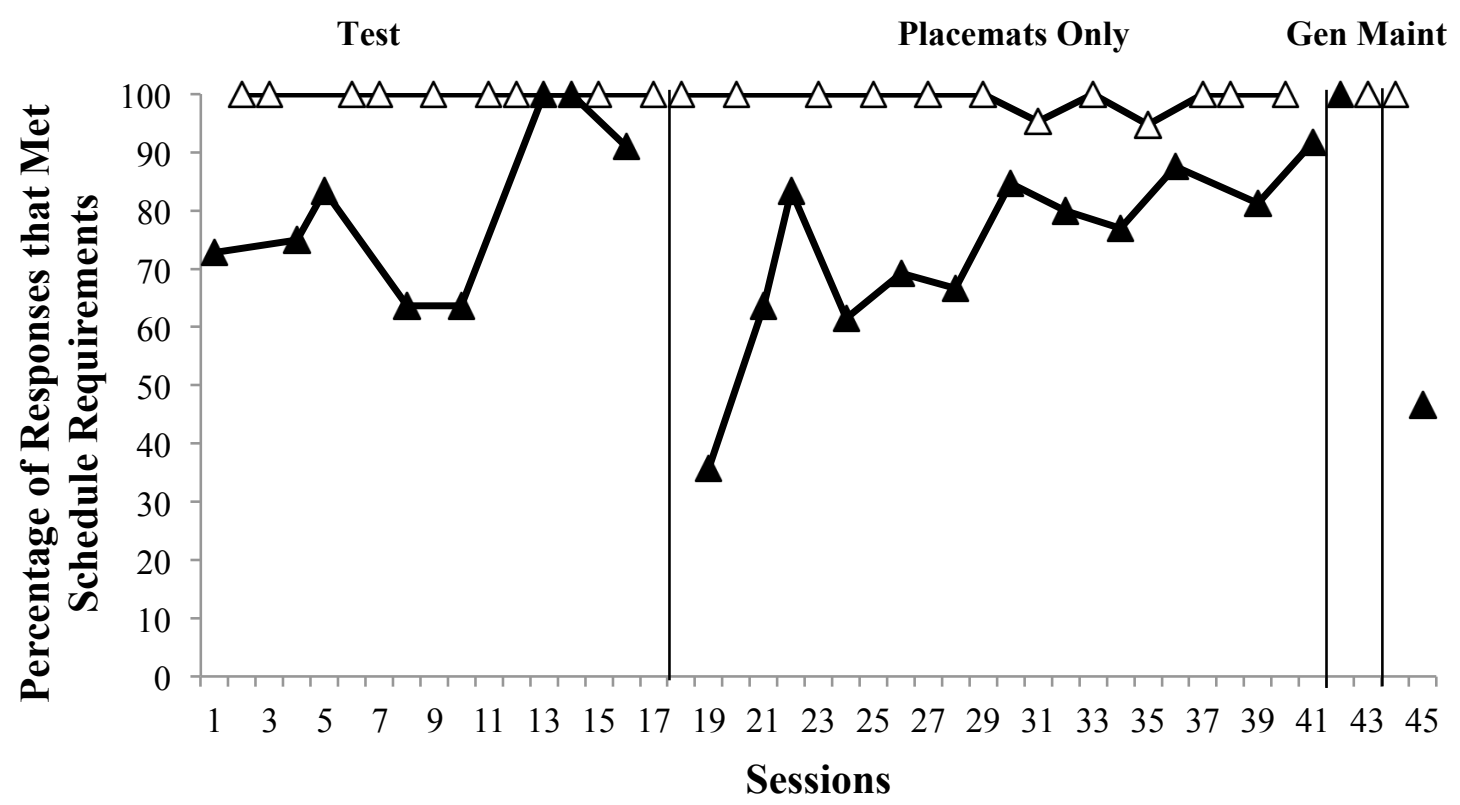

Figure 8. The percentage of Kade's responses that met schedule requirements once the scripts were removed. 
During the Placemats Only No Vary condition, the frequency of Kent's responding ranged from 4 to 33 mand frames per session.

The percentage of correct responses during the Placemats Only Vary condition was also variable (see Figure 4). Ranging from $2 \%$ to $100 \%$. Across all Placemats Only No Vary sessions, Kent's percentage of correct responses was 100\%. Finally, Kent engaged in his default mand frame (i.e., "I want___") more frequently than the scripted mand frames.

Gus. Gus engaged in his default mand frame (i.e., "I want___") across all Placemats Only Vary and No Vary sessions (see Figure 2). The frequency of Gus's mand

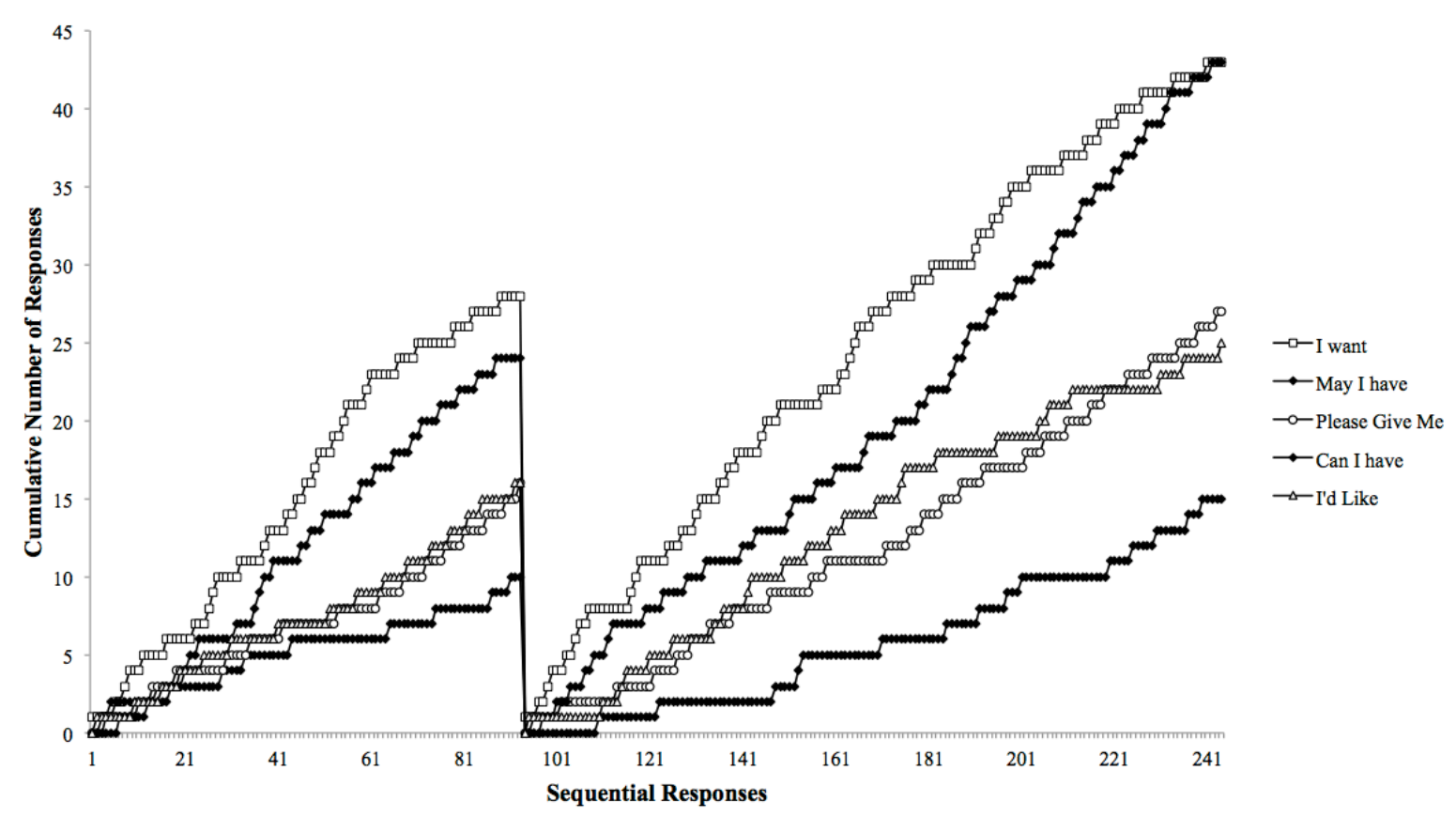

Figure 9. Kade's cumulative number of responses of each mand frame across the Test Vary Condition and the Placemats Only Condition. 
frames ranged from 14 to 19 during the Placemats Only Vary condition, and 15 to 20 during the Placemats Only No Vary condition.

Kade. During the Placemats Only Vary condition, Kade's mand variability ranged between four and five different scripted mand frames per session (see Figure 2). For all sessions when Kade engaged in four different mand frames per session, he omitted the response "May I have ___." Kade's frequency of mand frames ranged from 8 to 16 mand frames per session. During the Placemats Only No Vary condition, Kade engaged in the mand frame "I want ___ during all but two sessions. During the seventh Placemats Only No Vary session, Kade engaged in the mand frame "Can I have " one time. During the ninth Placemats Only No Vary session, Kade engaged in the mand frame "Please give me __ one time. During the Placemats Only No Vary condition, the frequency of Kade's mand frames ranged from 14 to 24 mand frames per session. Across all sessions, Kade did not engage in any novel mand frames. Kade's percentage of responses that met the Lag 3 schedule of reinforcement ranged from $35 \%$ to $91 \%$ across 12 Placemats Only Vary sessions (see Figure 8). Of note, Kade's responding gradually trends upward across this condition, ending at $91 \%$. Even though responses were reinforced regardless of whether they met the Lag 3 schedule, this measure provides insight about the nature of variability that occurred across the Placemats Only Vary sessions because higher scores indicate that responding is likely under the control of antecedent stimuli. 


\section{Return to Test Vary and No Vary Conditions}

Gus. Given that Gus did not demonstrate discriminated mand variability when the Lag 2 schedule of reinforcement was removed (i.e., in the Placemats Only Vary condition), we re-implemented the Lag 2 schedule of reinforcement in the presence of the green placemat and continued to only reinforce "I want " in the presence of the red placemat (see Figure 2). Gus continued to vary between 3 to 4 different mand frames (i.e., "I want ___ _, "May I have ___ "Can I get___ " " and "Can I have ___ ”) across eight Test Vary sessions, with his frequency of responding ranging from 8 to 28 responses per session. During the Test No Vary sessions, Gus engaged in "I want __ " across all sessions. During the third and fourth session of this condition, he engaged in the response form "May I have ___ one time during each session. The frequency of Gus's responding ranged from 8 to 24 responses per session during the Test No Vary sessions (see Figure 3).

\section{Generalization}

Kent. During the Generalization Vary session when all complete mand frames were reinforced, Kent engaged in four different mand frames (i.e., "I want ___," "May I have ___," "Please give me ___ " and "Can I get___ ”) for a total of 15 mand frames (see Figures 2 and 3). His percentage of correct responses for the Generalization Vary session was 53\%. During the No Vary session, Kent engaged in his default mand frame (i.e., "I want___ „ „) 34 times, with 100\% accuracy (see Figure 4).

Gus. During the Generalization Vary sessions when the Lag 2 schedule of reinforcement was in place, Gus engaged in three and four different mand frames, 
respectively (see Figure 2). Gus engaged in the novel mand frame "Can I have " during the second Generalization Vary session. During the Generalization No Vary sessions, Gus engaged in two and one different mand frames, respectively. During the session Gus engaged in two different mand frames, he engaged in the response "May I have ___ once, and otherwise engaged in the response "I want ___ " throughout the session. Across the Generalization Vary and No Vary sessions, Gus engaged in 23 and 26 total mand frames across the two Vary sessions, and 25 and 31 across the two Generalization No Vary sessions (see Figure 3). The percentage of correct responses across the Generalization Vary sessions was $62.5 \%$ and $83.8 \%$, respectively. The percentage of correct responses across the Generalization No Vary sessions was $92.3 \%$ and 100\%, respectively (see Figure 6).

Kade. During the Generalization Vary condition when all complete mand frames were reinforced, Kade engaged in five different mand frames (see Figure 2), with a frequency of eight mand frames for that session (see Figure 3). During the Generalization No Vary condition, Kade engaged in one mand frame (i.e., "I want "), with a frequency of 18 mand frames for that session. Across all Generalization Vary and No Vary sessions, Kade's percentage of correct responses was $100 \%$ (see Figure 8). Also, during the Generalization Vary session, Kade did not engage in any novel mand frames.

\section{Maintenance}

Kent. During the two week follow up, where all complete mand frames were reinforced, Kent engaged in four different mand frames during the Maintenance Vary 
session (see Figure 2), with a frequency of 13 mand frames (See Figure 3). During the Maintenance No Vary session, Kent engaged in one different mand frame, with a frequency of 39 mand frames. Kent's percentage of correct responses was $92.3 \%$ during the Maintenance Vary session, and 100\% during the Maintenance No Vary session (see Figure 4).

Gus. During the 2-week follow-up, when the Lag 2 schedule of reinforcement was in place. Gus engaged in three different mand frames during the Maintenance Vary session (see Figure 2), with a frequency of 21 mand frames (see Figure 3). When only "I want __ "was reinforced during the Maintenance No Vary session, Gus engaged in one different mand frame, with a frequency of 30 mand frames. The percentage of correct responses during was $90.4 \%$ during the Maintenance Vary session and $100 \%$ during the Maintenance No Vary session (see Figure 6).

Kade. During the two-week follow up when all complete mand frames were reinforced, Kade engaged in 4 different mand frames during the Maintenance Vary session, and 1 different mand frame during the Maintenance No Vary session (see Figure 2). During the Maintenance Vary session, he engaged in the novel mand frame "Will you give me ___, with a total of 15 mand frames throughout the session (see Figure 3). During the Maintenance No Vary session, he engaged in a total of 26 mand frames. The percentage of correct responses during the Maintenance Vary session was $46.6 \%$, and during the Maintenance No Vary session it was 100\% (see Figure 8). 
CHAPTER V

\section{DISCUSSION}

The purpose of this study was to assess the effects of a discrimination training procedure on (a) establishing discriminated variability when visual scripts were present, (b) maintaining discriminated variability when the visual scripts were removed, (c) establishing antecedent control of variability, (d) the generalization and maintenance of discriminated variability, and (e) the emission of novel mands. Below, the study is discussed in relation to these objectives. Implications for future research are also discussed.

\section{Discriminated Variability with Scripts Present}

Discriminated variability was established for all three participants when the visual scripts were present. This is supported by the demonstrated response variability during DT Vary sessions (green placemat with scripts present), and demonstrated response repetition during the DT No Vary sessions (red placemat with scripts present). However, the discrimination training procedures required modification in order for Gus's responding to come under the control of the green (vary) and red (no vary) placemats. It is unclear why the original procedures were not successful in establishing discriminated variability in Gus's responding. However, we demonstrated that Gus's behavior was under the control of researcher prompting, limiting the validity of our initial error correction procedures. During the Contingency Exposure condition, we prompted the first three responses of each session, and Gus continued to engage in varied or repetitive behavior during the DT Vary and DT No Vary sessions, respectively, without making an 
error. When we returned to our initial prompting procedures, where prompts were not provided until Gus engaged in an incorrect response, Gus engaged in varied responding during the No Vary probe. This suggests that Gus's behavior may have been under the control of researcher prompting at the beginning of the Contingency Exposure session and not the relevant visual stimuli.

Because Gus was not discriminating between the red and green placemats, we introduced the Alternating Placemats Condition. In this condition, each placemat was available for $75 \mathrm{~s}$ throughout the 5-min session. This provided Gus with the opportunity to contact the different contingencies that were associated with each placemat within each session instead of across each session. Following the Alternating Placemats Condition, we re-implemented our initial script training procedures, and we observed repetitive responding during the DT No Vary condition. As a result, the Alternating Placemats Condition was likely successful in establishing discriminative control of Gus's behavior when the visual scripts were present because, before this condition, Gus engaged in varied responding when the red placemat was present.

It is worth noting that the error correction procedures for the script training and discrimination training condition also required modification for Kent. However, these modifications were made because Kent was not acquiring the scripted mands. We hypothesized that Kent became reliant on researcher prompting, because Kent often turned around and pointed at the researcher who provided the prompts. To mitigate this, we provided three physical prompts before providing a vocal prompt. Combined with a series of booster sessions that were conducted to help Kent acquire the scripted mands 
(see above), these modifications were successful in establishing independent scripted responding.

\section{Discriminated Variability with Scripts Absent}

For all three participants, the $D T$ condition was successful in establishing independent variable responding. When the scripts were removed from the environment, mand variability continued to occur in the presence of the green placemat and the Lag schedule of reinforcement for all three participants. Also, repetitive responding continued to occur in the presence of the red placemat for all three participants. Both Kent and Kade independently engaged in all of the scripted mand frames that were taught during the script training condition. Kent, however, did not demonstrate mand variability until the third Test Vary session. The exact reasons for an initial lack of demonstrated response variability is unknown. A few possible explanations merit discussion, however. First, it is possible that, once the scripts were removed, the response effort of meeting the Lag 2 schedule of reinforcement suppressed responding. This is evidenced by the frequency of responses observed during the first two sessions (five responses and two responses, respectively). Second, it is possible that Kent's responding was sensitive to extinction. That is, the effects of extinction rapidly decreased his behavior. Sellers (2011) reported similar results with one participant (Michelle) who ceased engaging in variable responding when extinction contingencies were present. Though extinction may unintentionally suppress behavior, previous research suggests (e.g., Betz et al., 2011; Kelley, 2013; Sellers, 2011) that extinction is a necessary component in teaching mand variability. Third it is possible that Kent's challenging behavior competed with his 
requesting and, as a result, limited his frequency of mand frames. Given that the first two Test Vary sessions were conducted on one day, this explanation seems possible. During sessions on subsequent days, Kent engaged in varied manding and did not demonstrate challenging behavior. Though the exact reasons for Kent's initial lack of variability are unknown, future researchers may wish to examine variables that contribute to successful responding in the presence of Lag schedules in preschoolers with autism.

Though Gus continued to engage in varied responding, he did not engage in the scripted mand frame "Please give me ___ when the scripts were removed. The reason for the omission of this mand frame is not clear. It is possible that omission may be attributed to lack of exposure, but this explanation does not seem likely. Across the script training and discrimination training conditions, Gus received reinforcement for engaging in the scripted mand frame "Please give me __ " 65 times. Furthermore, we systematically randomized the sequence of prompts across all sessions in order to remove researcher bias towards a specific mand frame. Finally, the novel mand frame "Can I have __ condition. Each time it occurred, it was reinforced. Therefore, it seems unlikely that "Please give me __ _ did not occur because of lack of exposure to reinforcement, especially since the novel mand frame "Can I have ___ " continued to occur after the scripts were removed, despite having a limited history of reinforcement in the presence of the green placemat.

Given that multiple modifications were necessary to bring Gus's behavior under discriminative control during the script training and discrimination training condition, it is possible that the scripted frame "Please give me ___ failed to transfer to the control 
of the green placemat due to lack of attending behavior. As mentioned above, we demonstrated that Gus's responding was under the control of researcher prompting and not under the control of relevant visual stimuli. Given that Gus was, initially, not attending to the green and red placemats, it is possible that Gus was also not attending the scripts on those placemats. Therefore, it is possible that lack of attending contributed to this failure of transfer of stimulus control.

Finally it is possible that Gus's responding was more sensitive to consequence manipulations than antecedent manipulations. During later phases, when the Lag 2 schedule of reinforcement was removed from the environment, Gus's variability ceased. When the Lag 2 schedule of reinforcement was re-introduced, Gus's variability reemerged (see below for a detailed treatment of the Lag schedule's control over Gus's behavior). This demonstrated that consequence manipulations were a necessary factor in promoting Gus's variability. Furthermore, the Lag 2 schedule of reinforcement did not require the emission of all four scripted mand frames in order to earn access to reinforcement. The continued use of three mand frames would be enough to meet schedule requirements without making an error, so it's possible that this played a factor in the omission of "Please give me ___." However, both Kade and Kent continued to engage in all scripted mands during their respective Lag schedules, even though they could have engaged in fewer different mands and still earned access to reinforcement. Therefore, it is not clear whether or not the Lag 2 schedule of reinforcement had an unintended side-effect of suppressing mand variability. Though the reasons above outline the possible explanations for Gus's omission of "Please give me ___," the exact reason "Please give me ___ was not observed is unknown. 
It is worth noting that this study was the first study in this line of research to demonstrate successful mand variability in the absence of the scripts, or other visual cues that had one-to-one correspondence with the scripts (i.e., stickers), for all participants following script training. Betz et al. reported that one participant, Sellers reported that three participants, and Kelley reported that one participant failed to engaged in mand variability following script training, even when Extinction of Repetition contingencies were in place. However, there are multiple differences between the current study and previous studies that are worth noting. Two primary differences include the discrimination training procedure and the use of Lag schedules of reinforcement. Therefore, it is difficult to determine the exact mechanisms that were responsible for the differences in the reported results in comparison to previous studies in this area. It is also possible that the participants in this study had the necessary prerequisite skills to acquire mand variability, whereas the participants reported in previous studies did not. We attempted to account for differences between participants by recruiting individuals with similar repertoires of response variability. Regardless, future researchers may wish to conduct a component analysis to evaluate the variables that are necessary for the acquisition of varied manding. Future researchers may also wish to examine what prerequisite skills make the acquisition of varied manding more likely to occur.

It is worth noting that, once the scripts were removed, all three participants engaged in their default mand frame (i.e., "I want____) more frequently than other scripted mand frames across the Test Vary sessions. There are at least two possible reasons why this occurred. First, given that each participant's default mand frame was well established prior to the beginning of the study, it is possible that their default mand 
frame was at greater strength than the scripted mand frames (mand frames the participant was not using prior to the beginning of the study). This hypothesis is further supported by the observation that Kade's "Can I have ___ "was emitted almost as often as "I want ___." Given that Kade reliably engaged in "Can I have ___ during the Extinction of Repetition condition, it seems reasonable that this mand frame occurred more frequently than other mand frames because, in addition to "I want ___, it was in Kade's repertoire prior to the beginning of the study. A second explanation is that each participant's default mand frame was reinforced throughout all of the DT and Test No Vary sessions, and as a result, the research preparation may have unintentionally strengthened each participant's default mand frame. Though both of these explanations may have contributed to each participant's default mand frame occurring more frequently than any other responses, the exact reasons for why this happened are unknown.

Though the scope of this study was limited to mand variability, Gus's omitted mand frame "Please give me__ " highlight on the importance of not only teaching a repertoire of response variability, but also verifying those responses are strong in the individual's repertoire. Without this consideration, individuals with autism may not reliably vary their verbal behavior even when contingencies of reinforcement require it and variable responding has been reinforced in the past. Therefore, both response strength and the skill of being able to vary responses may be independent factors to consider when teaching individuals with autism to vary their verbal behavior. 


\section{Antecedent Control of Discriminated Variability}

Both Kade and Kent continued to engage in discriminated responding when the

Lag schedule of reinforcement was removed. This suggests that the research procedures established the green and red placemats as discriminative stimuli for varied and repetitive behavior, respectively, because the only difference between the Placemats Only conditions were the green and red placemats and the previous history of reinforcement associated with those placemats. In this condition, every complete mand frame was reinforced, but Kent and Kade continued to vary or repeat their requests during the Placemats Only Vary and No Vary sessions, respectively. It also suggests that stimulus control was transferred from the scripts to the placemats. To our knowledge, this is the first study to demonstrate discriminated variability of verbal behavior in individuals with autism. Furthermore, this is the first study to demonstrate that varied responding in individuals with autism can persist regardless of whether or not current contingencies of reinforcement require variability. This study also extends the research on generalization by demonstrating an effective strategy to program common stimuli into the natural environment (see Stokes \& Baer, 1977).

The results of this study also provide support for Skinner's (1957) analysis of audience control. Skinner defined an audience as "a discriminative stimulus in the presence of which verbal behavior is characteristically reinforced and ...therefore, is characteristically strong” (p. 172). In this study, we established two types of verbal behavior, response variability and response repetition that were strong in the presence of the green and red placemats, respectively. Though the green and red placemats do not 
resemble an audience member in a physical sense (that is, they are not living organisms), Skinner noted that location or other physical stimuli (in this case, the placemats) can exert strong control over verbal behavior (i.e., varied or repetitive behavior) because of their associated histories of reinforcement. This demonstration of audience control provides important implications to the analysis in verbal behavior because it provides a strategy for establishing different types of verbal behavior under different types of environmental conditions.

In this study Kade engaged in some varied responding during the Placemats Only No Vary condition. Each time Kade engaged a varied response during the Placemats Only No Vary condition, it was reinforced. However, Kade continued to engage in repetitive behavior (i.e., engage in the mand frame "I want___") throughout the remainder of the session and across other Placemats Only No Vary sessions. This provides further evidence for the strength of the discriminative control. Even though reinforcement was provided for response variability in the Placemats Only No Vary condition, Kade continued to reliably engage in repetitive responding for the remainder of the sessions. This likely occurred because of the strong control the red placemat had over Kade's verbal behavior.

Even though Kent demonstrated discriminated mand variability when the Lag 2 schedule of reinforcement was removed, we observed evidence that control of his responding may have shifted from antecedent to consequence control within some of the Placemats Only Vary sessions. For example, session 68 (Placemats Only Vary; see Figure 10), Kent engaged in the following sequence of mands: "I want ___," "Please give me ___," "Can I get ___, "May I have ___,, "I want ___,, "I want ___," 
"Please give me ," "May I have ," and "Please give me . Each response was reinforced. Then, for the rest of the session, Kent engaged in the default mand frame "I want " 10 more times, and he did not engage in any other mand frames. In all cases, "I want___ "was reinforced. This suggests that Kent's behavior was initially under the antecedent control of the green placemat. Then, after experiencing the contingencies (that all responses were reinforced, regardless of whether or not they were varied), he began to engage in responding that resembled that of baseline (i.e., repetitive responding). This pattern of responding provides support for previous research that suggests that repetitive behavior will likely occur when contingencies of reinforcement support it.

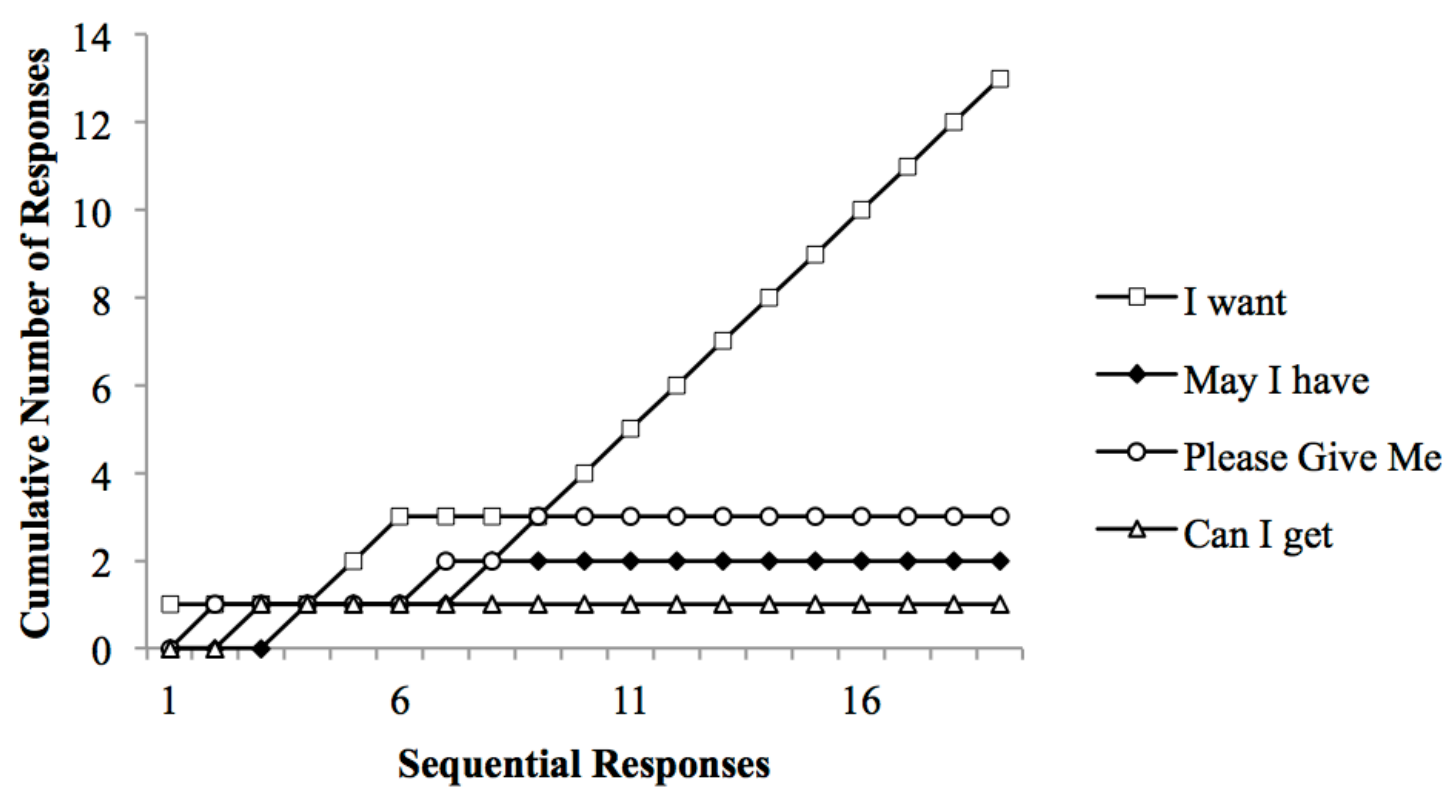

Figure 10. The cumulative number of Kent's responses of each mand frame across session 68 (Placemats Only Vary). 
Gus did not engage in variable responding during the Placemats Only condition. As a result, his responding decreased to baseline levels during the Placemats Only Vary sessions. This suggests that Gus's variability was not reliably under the control of the placemats. When we re-introduced the Lag 2 schedule of reinforcement following the Placemats Only condition, Gus's variable responding re-emerged. This replication of treatment effects verified that Gus's variable responding was primarily under the control of the Lag 2 schedule of reinforcement.

Though Gus did not demonstrate discriminated variability when the Lag 2 schedule of reinforcement was removed, he demonstrated some responding at the beginning of each research session during the Test Vary condition that may have been under discriminative control. Measuring responding at the beginning of each research session is an appropriate measure for stimulus discrimination (in this case, discriminated variability) because, prior to making an error (and experiencing the associated consequence of not receiving a reinforcer), any variable responding that occurs can be argued to be under antecedent control. During sessions 71, 72, 88, and 91 (Test Vary conditions) the first two responses of each session were varied mands. Furthermore, during sessions 84, and 92, and 95 (Test Vary conditions), the first 4, 12, and 4 responses, respectively, were also varied mands. This suggests that, in some instances, Gus engaged in variable manding that was under the control of the green placemat.

The exact reasons why Gus engaged in some discriminated variability prior to making an error (i.e., not meeting the Lag 2 schedule of reinforcement requirements) are unknown. However, it is possible that sequence effects contributed to discriminated variability prior to Gus making an error. For example, sessions 72, 84, and 92 were 
conducted after a Test Vary session, so it is possible that Gus's behavior was under the temporal control of the Lag 2 schedule of reinforcement from the previous Test Vary session. However, sessions 71, 88, 91, and 95 were conducted after a Test No Vary session, so the order of conditions may have only played a limited role.

It is also possible that Gus was slowly acquiring a repertoire of discriminated variability, whereas Kade and Kent acquired it more rapidly. Given that our experiment measured behavior over a short length of time, it is possible that additional exposure to the Lag 2 schedule of reinforcement would have been sufficient in bringing Gus's behavior under antecedent control of the green placemat. Future researchers should examine whether or not prolonged exposure to a Lag schedule of reinforcement can increase the probability of varied manding coming under discriminative control.

During the Test and Placemats Only No Vary condition, the frequency of Kade and Kent's responding was noticeably lower than in respective No Vary condition (see Figure 3). It is possible varied responding that occurs under the control of antecedent stimuli (i.e., the green placemat) is more effortful to emit than behavior under the control of its current consequences. As we mentioned above, Gus's behavior was likely under the control of its immediate consequences, and no noticeable differences were observed in his response rate between Test Vary and No Vary sessions. Therefore, it is possible that antecedent control (or lack thereof) can account for the observed differences in response rates.

Though the exact reason we observed different response rates between the Test and Placemats Only Vary and No Vary sessions for Kade and Kent is unknown, this observed difference contributes to the literature on response variability because, to date, 
no applied studies have compared response rate between a continuous schedule of reinforcement and Lag schedules. Second, to date, no applied studies have compared response rates between repetitive and varied responding. Therefore, this study contributes to the literature by being the first systematic examination of these variables.

\section{Generalization of Discriminated Variability}

Kade, Kent, and Gus demonstrated discriminated response variability during the Generalization sessions. This suggests that the stimulus control of the placemats was generalizable across conditions. This study provides further support for previous studies (e.g., Betz et al., 2011; Kelley, 2013; Sellers, 2011) that have demonstrated generalization of mand variability from the research to a natural setting.

\section{Maintenance of Discriminated Variability}

During the 2-week follow-up, Kent, Kade and Gus demonstrated discriminated variability. That is, Kade engaged in four mand frames during the Maintenance Vary session, and Gus engaged in three mand frames during the Maintenance Vary session. Both participants engaged in repetitive responding during the Maintenance No Vary session. For Kent and Kade, in the Maintenance Vary session, contingencies of reinforcement did not require response variability, yet variability continued to occur. This suggests that the research preparation can establish a repertoire of discriminated variability that can maintain over a short length of time. Because Gus's variability occurred during the Maintenance Vary session with the Lag schedule of reinforcement, 
his results suggest that children with autism may continue to respond to a Lag schedule of reinforcement after teaching ceases for a brief length of time.

\section{Emission of Novel Mand Frames}

Gus was the only participant to engage in novel mand frames throughout multiple conditions of the study. During the $D T$ condition, he engaged in the novel mand frame "May I get ___ " and "Can I have ___." However, the response "Can I have ___ "was observed during baseline, and therefore may be more appropriate to consider as a response that was already in Gus's repertoire, just not at strength. When the scripts were removed, he again engaged in the novel mand frame "Can I have .

Kade engaged in novel responding, but only during the two-week follow-up

Maintenance Vary session. He engaged in the response "Will you give me ___ one time. It is not clear why Kade did not engage in this mand frame during previous sessions of the study.

The results of this study do not align with previous research on mand variability with respect to novel responding. Betz et al. (2011) and Kelley (2013) each reported that, when variability occurred in the absence of scripts, novel responding was observed for all participants. In the case of this study, response variability successfully occurred in the absence of scripts for Kent, Kade, and Gus, but only Gus demonstrated novel responding. Kade's novel mand frame appears to be an exception to the rule, since it only occurred once.

It is not clear why Gus was the only participant to reliably exhibit novel responding. However, at least two explanations merit discussion. First, it is possible that 
the operational definition we used in this study was overly restrictive, and as a result, it did not capture novel responses made by Kade and Kent. However, we used the same operational definition as Betz et al. (2011) and Kelley (2013), so this explanation seems unlikely.

Second, Gus was the only participant whose behavior was not under discriminative control of the green and red placemats. It is possible that variables we did not account for were controlling his behavior. As a result, these unaccounted variables may have supported the emission of novel mands.

In this study we verified that Kade and Kent's responding was under the discriminative control of the placemats, and they did not engage in novel mands. It is possible then, that the stimulus control established by the research preparation did not support the emission of novel mands. Therefore, even though scripts were faded, novel manding did not occur because antecedent stimuli (i.e., the green and red placemats) were only associated with a history reinforcement for scripted manding. Though the above reasons may have contributed to the lack of novel responding reported in this study, the exact reasons for why limited novel responding was observed are unknown.

\section{Limitations and Future Directions}

There are multiple limitations of this study that are worth noting. It is unclear whether or not the participants would have varied their verbal behavior without undergoing the discrimination training procedure. As mentioned earlier, we used the discrimination training procedure as a strategy to evaluate whether or not variable responding could be placed under discriminative control. It is unclear how the 
discrimination training procedure compares in effectiveness in establishing mand variability with other script training and fading procedures. Therefore, future researchers may wish to systematically compare the discrimination training procedure with other script training strategies in establishing mand variability in preschoolers with autism.

It is unclear if the discrimination training procedure, the Lag schedule of reinforcement, our error correction procedures, or some combination were responsible for establishing variable responding when the scripts were removed. The current study was designed to mitigate procedural setbacks that were described in previous studies. However, a component analysis was not conducted to determine what parts of the intervention were necessary to establish independent mand variability. Given that this procedure successfully established mand variability for all three participants, future researchers may conduct a component analysis in order to determine the relative effectiveness of each part of the intervention. Of note, researchers may wish to examine the effectiveness of the Alternating Placemats Condition because it may decrease the length of time it takes to teach discriminated responding to children with autism.

Researchers may evaluate whether or not the No Vary condition is necessary component to establishing mand variability. During this study, we conducted a No Vary session for every Vary session. As a result, the experiment may have taken twice as long to conduct. Though conducting No Vary sessions may be instrumental in maintaining stimulus discrimination, it is not clear whether or not it is a necessary component to establishing mand variability, especially in a clinical setting. Also, that the No Vary condition suppressed responding may raise concerns regarding the social validity of the experimental procedure. Therefore, future researchers may wish to evaluate the necessity 
of the No Vary component. This would allow researchers to develop a strategy that is effective, efficient, and socially valid in establishing mand variability in individuals with autism.

As mentioned previously, Gus did not engage in the scripted mand "Please give me __ after the scripts were removed. Though the exact reasons why this occurred are unclear, future researchers may wish to examine how to increase the likelihood that individuals with autism engage in all responses in their repertoire of varied verbal behavior. Also, Gus did not engage in discriminated manding when the Lag schedule of reinforcement was removed. In order to better understand strategies for establishing verbal behavior that is under discriminative control, future researchers may wish to examine strategies that bring behavior under discriminative control in all cases.

Since this study did not produce novel manding in all participants, future researchers may wish to examine strategies to increase the probability that novel responses will occur. Novel responding in the context of variability may be an important area of research to consider because it would allow for an individual with autism to continue to engage in responses if their well-established responses in their repertoire fail to produce access to reinforcement.

Since this research study focused on establishing discriminated variability in manding, the effects of this procedure on establishing discriminated variability for other verbal operants (e.g., echoics or intraverbals) are unknown. However, we have provided a foundation for researchers to build an understanding of how verbal behavior can come under discriminative control. Ultimately, a broad understanding of discriminative control of verbal behavior can help to improve the social outcomes of individuals with autism. 
Only three individuals participated in this study, so the extent to which the results of this study generalize across additional participants is unknown. Therefore, future researchers should replicate this research with additional participants to examine the external validity of the results.

In summary, this is the first research study on mand variability to successfully demonstrate continued variable responding when the scripts were faded from the environment for all three participants. This is also the first research study that demonstrated stimulus control over varied verbal behavior in individuals with autism. Furthermore, this is the first applied research study on response variability that demonstrated that individuals with autism can continue to vary their verbal behavior in the presence of antecedent stimuli that have been associated with a history of response variability. This study also provides insight on how discriminative stimuli (visual cues) may be used to control complex verbal behavior in individuals with autism. 


\section{REFERENCES}

Betz, A. M., Higbee, T. S., Kelley, K. N., Sellers, T. P., \& Pollard, J. S. (2011).

Increasing response variability of mand frames with script training and extinction. Journal of Applied Behavior Analysis, 44(2), 357-362. doi:10.1901/jaba.2011.44357.

Carr, J. E., Nicolson, A. C., \& Higbee, T. S. (2000). Evaluation of a brief multiplestimulus preference assessment in a naturalistic context. Journal of Applied Behavior Analysis, 33(3), 353-357

DeLeon, I. G., \& Iwata, B. A. (1996). Evaluation of a multiple-stimulus presentation format for assessing reinforce preferences. Journal of Applied Behavior Analysis, 29, 519-533.

Denney, J., \& Neuringer, A. (1998). Behavioral variability is controlled by discriminative stimuli. Animal Learning and Behavior, 26(2), 154-162.

Goetz, E. M., \& Baer, D. M. (1973). Social control of form diversity and the emergence of new forms in children's blockbuilding. Journal of Applied Behavior Analysis, 6(2), 209-217.

Kelley, K. N. (2013). The effects of simultaneous script-training and fading procedures on the mand variability of children with autism (Unpublished doctoral dissertation). Utah State University, Logan, UT.

Lee, R. (2007). The effects of script-fading and a lag-1 schedule on varied responding in children with autism. (Unpublished doctoral dissertation). City University of New York, New York, NY. 
Lee, R., McComas, J. J., \& Jawor, J. (2002). The effects of differential and lag reinforcement schedules on varied verbal responding by individuals with autism. Journal of Applied Behavior Analysis, 35(4), 391-402.

Lee, R., \& Sturmey, P. (2006). The effects of lag schedules and preferred materials on variable responding in students with autism Journal of Autism and Developmental Disorders, 36(3), 421-428.

Miller, N. (2012). Stimulus control and generalization of operant variability in the block play of children with autism (Electronic thesis or dissertation). Retrieved from https://etd.ohiolink.edu/

Neuringer, A. (2002). Operant variability: Evidence, functions, and theory. Psychonomic Bulletin and Review, 9(4), 672-705.

Page, S., \& Neuringer, A. (1985). Variability is an operant. Journal of Experimental Psychology: Animal Behavior Processes, 11(3), 429-452. doi:10.1037//00977403.11.3.429

Pryor, K. W., Haag, R., \& O’Reilly, J. (1969). The creative porpoise: Training for novel behavior. Journal of the Experimental Analysis of Behavior, 12(4), 653-661.

Schwartz, B. (1980). Development of complex, stereotyped behavior in pigeons. Journal of the Experimental Analysis of Behavior, 33, 153-166.

Schwartz, B. (1982). Reinforcement-induced behavioral stereotypy: How not to teach people to discover rules. Journal of the Experimental Analysis of Behavior, 111, 23-59.

Sellers, T. P. (2011). Increasing mand variability in preschoolers with autism (Unpublished doctoral dissertation). Utah State University, Logan, UT. 
Skinner, B. F. (1953). Science and human behavior. New York; NY: The Free Press.

Skinner, B. F. (1957). Verbal behavior. New York; NY: Appleton-Century-Crofts.

Skinner, B. F. (1981). Selection by consequences. Science, 213, 501-504.

Stokes, T. F., \& Baer, D. M. (1977). An implicit technology of generalization. Journal of Applied Behavior Analysis, 10(2), 349-367.

Susa, C., \& Schlinger, H.D. (2012). Using a lag schedule to increase variability of verbal responding in an individual with autism. The Analysis of Verbal Behavior, 28, 125-130. 


\section{APPENDIX}

Data Sheets 


\section{Treatment Integrity Data Sheet}

Date: Data Collector:

Participant:

Session

Number:

Directions: Mark whether or not each component occurred.

1) Ten edible items were presented in MSWO

Y N N/A

2) Three edible items were identified in MSWO

Y N N/A

3) Researcher said, "It's time for snack" to start research session

Y N N/A

4) Timer was set to 5-min

Y N N/A

5) The correct placemat was put on the table

Y N N/A

6) The correct colored square was placed on the door of the research room

Y N N/A

7) Researcher started timer after saying "It's time for snack"

Y N N/A

8) Researcher stopped session after 5-min elapsed

Y N N/A

9) Responses that met reinforcement criteria were reinforced throughout session $\mathrm{Y} \mathrm{N} \mathrm{N} / \mathrm{A}$

10) Responses that did not meet rein. criteria were ignored throughout session $\quad \mathrm{Y} \mathrm{N} \mathrm{N} / \mathrm{A}$

11) Prompts were provided if no responding occurred after 15-s

Y N N/A

12) Prompts were provided in the correct sequence throughout the session

Y N N/A

13) The participant was seated across the table from the research assistant

Y N N/A

14) Prompts were only provided from behind the participant

Y N N/A

15) The correct prompt sequence data sheet was used

Y N N/A

\begin{tabular}{|c|}
\hline \# of Y: \\
\# of opp (exclude NA): \\
\% Correct \\
\hline
\end{tabular}


Baseline Data Sheet

Participant:

Date: Instructor:

Session Number:

MAIN/RELI

Mand (word for word, in sequential order)

Total FULL Mands

Total DIFFERENT

Mands 
Script Training DATA SHEET KADE A Vary Condition

Date: Instructor:

Session Number:

MAIN/RELI

\begin{tabular}{|c|c|c|}
\hline Prompt Sequence & Mand Frame & I PP, VP? \\
\hline Can I have & & $\begin{array}{lll}\text { I } & P & \text { VP }\end{array}$ \\
\hline May I have & & I P VP \\
\hline I'd like & & I P VP \\
\hline I want & & I P VP \\
\hline Please give me & & I P VP \\
\hline May I have & & I P VP \\
\hline Can I have & & I P VP \\
\hline I want & & I P VP \\
\hline Please give me & & I P VP \\
\hline I'd like & & I P VP \\
\hline I want & & I P VP \\
\hline May I have & & I P VP \\
\hline Can I have & & I P VP \\
\hline Please give me & & I P VP \\
\hline I'd like & & I P VP \\
\hline I want & & I P VP \\
\hline May I have & & I P VP \\
\hline Please give me & & I P VP \\
\hline I'd like & & I P VP \\
\hline Can I have & & I P VP \\
\hline I want & & I P VP \\
\hline May I have & & I P VP \\
\hline Please give me & & I P VP \\
\hline I'd like & & I P VP \\
\hline Can I have & & I P VP \\
\hline May I have & & I P VP \\
\hline I want & & I P VP \\
\hline Please give me & & I P VP \\
\hline May I have & & I P VP \\
\hline I want & & $\begin{array}{lll}\text { I } & P & \text { VP }\end{array}$ \\
\hline
\end{tabular}


Script Training DATA SHEET KADE B Vary Condition

Date: Instructor:

Session Number:

MAIN/RELI

\begin{tabular}{|c|c|c|}
\hline Prompt Sequence & Mand Frame & I PP, VP? \\
\hline Please give me & & I P VP \\
\hline I want & & I P VP \\
\hline I'd like & & I P VP \\
\hline Can I have & & I P VP \\
\hline Please give me & & I P VP \\
\hline May I have & & I P VP \\
\hline I'd like & & I P VP \\
\hline I want & & I P VP \\
\hline May I have & & I P VP \\
\hline Can I have & & I P VP \\
\hline Please give me & & I P VP \\
\hline I'd like & & I P VP \\
\hline May I have & & I P VP \\
\hline I want & & I P VP \\
\hline Can I have & & I P VP \\
\hline Please give me & & I P VP \\
\hline I'd like & & I P VP \\
\hline I want & & I P VP \\
\hline May I have & & I P VP \\
\hline Can I have & & I P VP \\
\hline I'd like & & I P VP \\
\hline Please give me & & I P VP \\
\hline May I have & & I P VP \\
\hline I want & & I $\quad \mathbf{P}$ VP \\
\hline I'd like & & I P VP \\
\hline Can I have & & I P VP \\
\hline Please give me & & I P VP \\
\hline May I have & & I P VP \\
\hline I want & & I P VP \\
\hline Can I have & & I P VP \\
\hline
\end{tabular}


Script Training DATA SHEET KADE C Vary Condition

Date: Instructor:

Session Number:

MAIN/RELI

\begin{tabular}{|c|c|c|}
\hline Prompt Sequence & Mand Frame & I PP, VP? \\
\hline Please give me & & I P VP \\
\hline I'd like & & I P VP \\
\hline May I have & & I P VP \\
\hline Can I have & & I P VP \\
\hline I want & & I P VP \\
\hline I'd like & & I P VP \\
\hline Please give me & & I P VP \\
\hline Can I have & & I P VP \\
\hline May I have & & I P VP \\
\hline I'd like & & I P VP \\
\hline I want & & I P VP \\
\hline Please give me & & I P VP \\
\hline Can I have & & I P VP \\
\hline May I have & & I P VP \\
\hline I'd like & & I P VP \\
\hline Please give me & & I P VP \\
\hline Can I have & & I P VP \\
\hline I want & & I P VP \\
\hline May I have & & I P VP \\
\hline Please give me & & I P VP \\
\hline I'd like & & I P VP \\
\hline I want & & I P VP \\
\hline May I have & & I P VP \\
\hline Can I have & & I P VP \\
\hline Please give me & & I P VP \\
\hline I'd like & & I P VP \\
\hline I want & & I P VP \\
\hline Can I have & & I P VP \\
\hline May I have & & I P VP \\
\hline
\end{tabular}


Script Training DATA SHEET KADE D Vary Condition

Date:_Instructor: Session Number:

MAIN/RELI

\begin{tabular}{|c|c|c|}
\hline Prompt Sequence & Mand Frame & I PP, VP? \\
\hline May I have & & I $\mathbf{P}$ VP \\
\hline I'd like & & I P VP \\
\hline I want & & I P VP \\
\hline Can I have & & I P VP \\
\hline Please give me & & I P VP \\
\hline May I have & & I P VP \\
\hline I'd like & & I P VP \\
\hline I want & & I P VP \\
\hline Can I have & & I P VP \\
\hline May I have & & I P VP \\
\hline Please give me & & I P VP \\
\hline I'd like & & I P VP \\
\hline Can I have & & I P VP \\
\hline I want & & I P VP \\
\hline May I have & & I P VP \\
\hline Please give me & & I P VP \\
\hline I'd like & & I P VP \\
\hline I want & & I P VP \\
\hline Can I have & & I P VP \\
\hline May I have & & I P VP \\
\hline Please give me & & I P VP \\
\hline I want & & I P VP \\
\hline Can I have & & I P VP \\
\hline I'd like & & I P VP \\
\hline May I have & & I P VP \\
\hline Please give me & & I P VP \\
\hline Can I have & & I P VP \\
\hline I want & & I P VP \\
\hline I'd like & & I P VP \\
\hline Please give me & & I P VP \\
\hline
\end{tabular}


Script Training No Vary Condition Data Sheet

Participant:

Date: Instructor:

\begin{tabular}{|c|c|c|}
\hline Prompt Sequence & Mand Frame & I, PP,VP? \\
\hline I want & & I PP VP \\
\hline I want & & I PP VP \\
\hline I want & & I PP VP \\
\hline I want & & I PP VP \\
\hline I want & & I PP VP \\
\hline I want & & I PP VP \\
\hline I want & & I PP VP \\
\hline I want & & I PP VP \\
\hline I want & & I PP VP \\
\hline I want & & I PP VP \\
\hline I want & & I PP VP \\
\hline I want & & I PP VP \\
\hline I want & & I PP VP \\
\hline I want & & I PP VP \\
\hline I want & & I PP VP \\
\hline I want & & I PP VP \\
\hline I want & & I PP VP \\
\hline I want & & I PP VP \\
\hline I want & & I PP VP \\
\hline I want & & I PP VP \\
\hline I want & & I PP VP \\
\hline I want & & I PP VP \\
\hline I want & & I PP VP \\
\hline I want & & I PP VP \\
\hline I want & & I PP VP \\
\hline I want & & I PP VP \\
\hline I want & & I PP VP \\
\hline I want & & I PP VP \\
\hline
\end{tabular}




\section{Script Training DATA SHEET A Vary Condition Participant:}

Date:__ Instructor:

\begin{tabular}{|c|c|c|}
\hline Prompt Sequence & Mand Frame & I PP, VP? \\
\hline Can I get & & I P VP \\
\hline May I have & & I P VP \\
\hline Please give me & & I P VP \\
\hline I want & & I P VP \\
\hline May I have & & I P VP \\
\hline Can I get & & I P VP \\
\hline Please give me & & I P VP \\
\hline I want & & I P VP \\
\hline Can I get & & I P VP \\
\hline May I have & & I P VP \\
\hline I want & & I P VP \\
\hline Please give me & & I P VP \\
\hline Can I get & & I P VP \\
\hline May I have & & I $\quad \mathbf{P} \quad \mathbf{V P}$ \\
\hline I want & & I P VP \\
\hline Can I get & & I P VP \\
\hline Please give me & & I P VP \\
\hline May I have & & I P VP \\
\hline Can I get & & I P VP \\
\hline I want & & I P VP \\
\hline May I have & & I P VP \\
\hline Can I get & & I P VP \\
\hline Please give me & & I P VP \\
\hline May I have & & I P VP \\
\hline I want & & I P VP \\
\hline Please give me & & I P VP \\
\hline May I have & & I P VP \\
\hline
\end{tabular}

MAIN/RELI 
Script Training DATA SHEET B Vary Condition

Participant:

Date: Instructor:

Session Number:

MAIN/RELI

\begin{tabular}{|c|c|c|}
\hline Prompt Sequence & Mand Frame & I PP, VP? \\
\hline Please give me & & I P VP \\
\hline May I have & & I P VP \\
\hline I want & & I P VP \\
\hline Can I get & & I P VP \\
\hline May I have & & I P VP \\
\hline Please give me & & I P VP \\
\hline Can I get & & I P VP \\
\hline I want & & I P VP \\
\hline May I have & & I P VP \\
\hline Please give me & & I P VP \\
\hline Can I get & & I P VP \\
\hline I want & & I P VP \\
\hline May I have & & I P VP \\
\hline Can I get & & I P VP \\
\hline Please give me & & I P VP \\
\hline I want & & I P VP \\
\hline May I have & & I P VP \\
\hline Can I get & & I P VP \\
\hline Please give me & & I P VP \\
\hline I want & & I P VP \\
\hline May I have & & I P VP \\
\hline Please give me & & I P VP \\
\hline Can I get & & I P VP \\
\hline May I have & & I P VP \\
\hline I want & & I P VP \\
\hline Please give me & & I P VP \\
\hline Can I get & & I P VP \\
\hline Please give me & & I P VP \\
\hline May I have & & I P VP \\
\hline
\end{tabular}


Script Training DATA SHEET C Vary Condition

Participant:

Date: Instructor:

Session Number:

MAIN/RELI

\begin{tabular}{|c|c|c|}
\hline Prompt Sequence & Mand Frame & I PP, VP? \\
\hline Please give me & & I P VP \\
\hline May I have & & I P VP \\
\hline Can I get & & I P VP \\
\hline I want & & I P VP \\
\hline May I have & & I P VP \\
\hline Please give me & & I P VP \\
\hline I want & & I P VP \\
\hline Can I get & & I P VP \\
\hline May I have & & I P VP \\
\hline Please give me & & I P VP \\
\hline Can I get & & I P VP \\
\hline May I have & & I P VP \\
\hline I want & & I P VP \\
\hline Please give me & & I P VP \\
\hline May I have & & I P VP \\
\hline I want & & I P VP \\
\hline Please give me & & I P VP \\
\hline May I have & & I P VP \\
\hline Can I get & & I P VP \\
\hline I want & & I P VP \\
\hline May I have & & I P VP \\
\hline Please give me & & I P VP \\
\hline Can I get & & I P VP \\
\hline May I have & & I P VP \\
\hline I want & & I P VP \\
\hline Can I get & & I P VP \\
\hline May I have & & I P VP \\
\hline Please give me & & I P VP \\
\hline Can I get & & I P VP \\
\hline
\end{tabular}


Script Training DATA SHEET D Vary Condition

Participant:

Date: Instructor:

Session Number:

MAIN/RELI

\begin{tabular}{|c|c|c|}
\hline Prompt Sequence & Mand Frame & I PP, VP? \\
\hline Can I get & & I P VP \\
\hline Please give me & & I P VP \\
\hline May I have & & I P VP \\
\hline I want & & I P VP \\
\hline Can I get & & I P VP \\
\hline Please give me & & I P VP \\
\hline I want & & I P VP \\
\hline May I have & & I P VP \\
\hline Can I get & & I P VP \\
\hline I want & & I P VP \\
\hline Please give me & & I P VP \\
\hline Can I get & & I P VP \\
\hline May I have & & I P VP \\
\hline Please give me & & I P VP \\
\hline I want & & I P VP \\
\hline Can I get & & I P VP \\
\hline May I have & & I P VP \\
\hline I want & & I P VP \\
\hline Please give me & & I P VP \\
\hline Can I get & & I P VP \\
\hline May I have & & I P VP \\
\hline I want & & I P VP \\
\hline Please give me & & I P VP \\
\hline May I have & & I P VP \\
\hline Can I get & & I P VP \\
\hline Please give me & & I P VP \\
\hline I want & & I P VP \\
\hline
\end{tabular}




\section{Post Script Training Data Sheet}

Date:

Instructor:

Session Number:

MAIN/RELI

Mand Frame 
CURRICULUM VITAE

\author{
Matthew T. Brodhead
}

Education History

Doctor of Philosophy in Disability Disciplines (Applied Behavior Analysis Track), Utah State University (USU), Logan, $U T$

○ 2010-2014 (expected)

- Advisor: Thomas S. Higbee, Ph.D., BCBA-D

Master of Arts in Behavior Analysis, Western Michigan University (WMU), Kalamazoo, MI

- 2008-2010

- GPA: 4.0

- Advisor: Richard W. Malott, Ph.D., BCBA-D

Bachelor of Science, WMU, Kalamazoo, MI

- 2003-2008

- Major: Psychology

- Minor: Practical Writing

Waikato University, New Zealand (Study Abroad)

○ July 2007-November 2007

Academic Work History

Assistant Professor of Educational Studies (Tenure Track), Purdue University, West Lafayette, Indiana

- Starting August 18, 2014

\title{
Certifications
}

- $\quad$ Board Certified Behavior Analyst (\#1-10-7289)

Awards

- 2013 Nevada Association for Behavior Analysis Student Research Award

- 2011 Graduate Teaching Assistant of the Year for the USU Department of Special Education and Rehabilitation

- Nominated for the "Faculty and Staff of the Month" award by the USU National Residence Hall Honorary (November, 2011)

Publications in Print or Press

- Pollard, J. S., Higbee, T. S., Akers, J. S., \& Brodhead, M. T. (in press). An evaluation of an interactive computer training to teach instructors to implement discrete trials with children with autism. Journal of Applied Behavior Analysis.

- Brodhead, M. T., Higbee, T. S., Pollard, J. S., Akers, J. S., \& Gerencser, K. S. (in press). The use of linked activity schedules to teach children with autism to play hide-and-seek. Journal of Applied Behavior Analysis.

- Brodhead, M. T., Durán, L., \& Bloom, S. E. (2014). Cultural and linguistic diversity in recent language acquisition research on individuals with disabilities: a review and implications for research and practice. The Analysis of Verbal Behavior. doi:10.1007/s40616-014-0009-8

- Brodhead, M. T. (2014). Transition to Adult Life for Persons With Disabilities ed. by K. Storey, P. Bates, and D. Hunter. Education and Treatment of Children, 37, 163-168. doi:10.1353/etc.2014.0002 
Publications in Print or Press (cont.)

- Brodhead, M. T., \& Higbee, T. S. (2012). Teaching and maintaining ethical behavior in a professional organization. Behavior Analysis in Practice, 5(2), 86-92.

- Steuer, S. M. B., \& Brodhead, M. T. (2011). Experimentation in an academic library: a case study in security and individual student engagement. Journal of Library Innovation, 2, 35-44.

Publications in Preparation or Under Review

- Higbee, T. S., \& Brodhead, M. T. (in preparation). Promoting independence, verbal behavior, and social skills in individuals with autism through activity schedules and script fading.

- Field, S., Quigley, S., \& Brodhead, M. T. (in preparation). Cultural-competency as it relates to delivering behavior-analytic services.

- Brodhead, M. T., Higbee, T. S., Gerencser, K. S., \& Akers, J. S. (in preparation). The use of a discrimination training procedure to teach mand variability to preschoolers with autism.

Non-refereed Publications

- Higbee, T. S., Brodhead, M. T., \& Akers, J. S. (2012). Everyday strategies for promoting language in the home for children with autism. American Association for Home-based Early Interventionists News Exchange, 17, 2.

Grant Proposals Under Review

- Brodhead, M. T. (03/14, \$500). The use of a discrimination training procedure to teach mand variability to preschoolers with autism. Proposal submitted to the Association for Behavior Analysis Verbal Behavior Special Interest Group.

Oral Presentations Given

- Brodhead, M. T. (2013, October). The use of linked activity schedules to teach children with autism to play hide-and-seek. Invited paper presentation at the annual Nevada Association for Behavior Analysis Conference in Reno, NV.

- Brodhead, M. T., \& Higbee, T. S. (2013, May). Teaching and maintaining ethical behavior in a professional organization. Paper presented at the annual Association for Behavior Analysis Conference in Minneapolis, MN.

- Austin, A. K., Higbee, T. S., Brodhead, M. T., \& Boyle, M. A. (2013, May). Evaluating the effects of reinforcer choice and reinforcer variation on response rates in children with autism. Paper presented at the annual Association for Behavior Analysis Conference in Minneapolis, MN.

- Akers, J. S., Hartzheim, D. U., Brodhead, M. T., Higbee, T. S., Pollard, J. S., \& Kelley, K. N. (2013, April). Teaching social skills to children with autism and improving employee implementation of discrete trial via E-learning. Presentation given at the Utah Valley University conference on autism in Provo, UT.

- Brodhead, M. T., Durán, L., \& Bloom, S. E. (2012, June). Cultural and linguistic diversity in recent language acquisition research. Paper presented at the annual Utah Association for Behavior Analysis Conference in Logan, UT.

- Brodhead, M. T., Higbee, T. S., Pollard, J. S., \& Akers, J. S. (2012, May). The use of activity schedules to promote social and on-task behavior in children with autism during a game of hide and seek. Paper presented at the annual Association for Behavior Analysis Conference in Seattle, WA.

- Austin, A. K., Higbee, T. S., Brodhead, M. T., \& Boyle, M. A. (2012, February). Evaluating the effects of reinforcer choice and reinforcer variation on response rates in children with autism. Paper presented at the annual California Association for Behavior Analysis Conference in Anaheim, CA.

- Brodhead, M. T., Higbee, T. S., Pollard, J. S., \& Akers, J. S. (2012, February). The use of activity schedules to promote social and on-task behaviors in children with autism during a game of hide and seek. Paper presented at the annual California Association for Behavior Analysis Conference in Anaheim, CA. 
Oral Presentations Given (cont.)

- Austin, A., Brodhead, M. T., \& Higbee, T. S. (2010, October). Effective strategies for preventing, reducing, and replacing challenging behavior in young children. Presentation given at Utah Early Childhood Special Education Conference in Provo, UT.

Poster Presentations Given

- Brodhead, M. T., Higbee, T. S., Pollard, J. S., \& Akers, J. S. (2012, June). The use of activity schedules to promote social and on-task behavior in children with autism during a game of hide and seek. Poster presented at the annual Utah Association for Behavior Analysis Conference in Logan, UT.

- Brodhead, M. T., Higbee, T. S., Pollard, J. S. (2012, January). Using activity schedules to promote social and on-task behavior during a game of hide-and-seek. Poster presented at the São Paulo School for Advanced Science: Advances in Research and Treatment of Autistic Behavior, São Carlos, Brazil.

- Brodhead, M. T., Higbee, T. S., Pollard, J. S., \& Hartzheim, D. (2011, October). The use of activity schedules to promote social and on-task behaviors in children with autism during a game of hide and seek. Poster presented at the annual Nevada Association for Behavior Analysis Conference in Reno, NV.

- Brodhead, M. T., Gaisford, K. L, Chow, W. T., Hartley, B. \& Malott, R. W. (2010, February). Practical considerations for function based treatment in an early childhood developmentally delayed classroom. Poster presented at the Association for Behavior Analysis Autism Conference.

- Brodhead, M. T., Budzen, M., Baumgartner, M., \& Malott, R. W. (2009, May). Academic selfmanagement. Poster presented at the Association for Behavior Analysis International Conference.

- Brodhead, M. T., Budzen, M., Baumgartner, M., \& Malott, R. W. (2009, February). Academic selfmanagement. Poster presented at the Behavior Analysis Association of Michigan Conference.

- Rau, A., Crooks, B., Brodhead, M. T., Fox, C., \& Malott, R. W. (2007, May). Self-management: a molecular analysis. Poster presented at the Association for Behavior Analysis Conference.

- Brodhead, M. T., Fox, C., Rau, A., Crooks, B., \& Malott, R. W. (2007, March). Self-management: a molecular analysis. Poster session presented at the Behavior Analysis Association of Michigan Conference.

Editorial Activities

- Reviewer, Journal of Applied Behavior Analysis: 2011, 2012, 2013, 2014

- Reviewer, Behavior Analysis in Practice: 2010

\section{Workshops Given}

- Brodhead, M. T., Akers, J. S., \& Higbee, T. S. (2012, June). Considering ethical behavior in educational settings: Parts 1 and 2. Workshop given at the annual Effective Practices Conference in Logan, UT.

- $\quad$ Akers, J. S., Brodhead, M. T., \& Higbee, T. S. (2012, June). Using activity schedules to promote independence between young children. Workshop given at the annual Effective Practices Conference in Logan, UT.

- Brodhead, M. T., Pollard, J. S., Akers, J. S., Hartzheim, \& Higbee, T. S. (2012, February). Ethical considerations for applied behavior analysts. Workshop given at the annual meeting of the California Association for Behavior Analysis in Anaheim, CA.

- Brodhead, M. T. \& Higbee, T. S. (2011, June). Using activity schedules to promote independence in early learners. Workshop given at the annual Effective Practices Conference in Logan, UT.

- Austin, A., Brodhead, M. T., Sellers, T., \& Higbee, T. S. (2011, February). Ethical considerations for applied behavior analysts. Workshop given at the annual meeting of the California Association for Behavior Analysis in Burlingame, CA. 
Teaching Experience

USU Special Education 5010: Applied Behavior Analysis 1: Principles, Assessment, and Analysis

- Position: Instructor

- Duration: Fall, 2012

USU Special Education 4000: Education of Exceptional Individuals

○ Position: Instructor

- Duration: Fall, 2011

Teaching Experience (cont.)

USU Special Education 4000: Education of Exceptional Individuals

- Position: Teaching Assistant

○ Duration: Spring, 2011

USU Special Education 5010: Applied Behavior Analysis 1: Principles, Assessment, and Analysis

○ Position: Teaching Assistant

- Duration: Fall, 2010

WMU Psychology 3600: Rat Lab

- Position: Graduate Student Instructor

- Duration: Fall, 2008 - Spring, 2010

WMU Psychology 1000H: Honors Psychology

- Position: Graduate Student Instructor

- Duration: Fall, 2008 - Spring, 2009

WMU Psychology 3960: Self-Management

- Position: Graduate Student Instructor

○ Duration: Fall, 2008 - Spring, 2010

Administrative Duties

- Elected Student Representative to the Utah Association for Behavior Analysis for 2011-2013

- Elected Student Representative to the Disability Disciplines Doctoral Program Committee for 20122013

- International member of the 2012 São Paulo School for Advanced Science organizing committee

Clinical and Consultation Experience (Graduate School)

Behavioral Consultant for Granite School District, UT (via USU)

○ Position: Behavioral Consultant

○ Duration: September, 2011 - Current

- Primary responsibility: Provide on-site and distance training and consultation for ABA-based preschool and kindergarten classrooms.

Autism Support Services: Education Research and Training (ASSERT), Center for Persons with

Disabilities, Logan, $U T$

- Position: Behavior Analyst

- Duration: May, 2010 - Current

- Primary responsibility: Oversee the implementation of academic programing for preschoolers with autism.

Kalamazoo Community Mental Health Psychological Assessment and Treatment

Services

- Position: Lead Therapist

○ Duration: August, 2009 - May, 2010

- Primary responsibility: Design and implement behavior plans for adults with disabilities.

Special Populations Practicum, Croyden Avenue School, Kalamazoo, MI

- Position: Supervisor and Case Coordinator

○ Duration: May, 2009 - May, 2010

- Primary responsibility: Supervise the implementation of discrete trial instruction.

Special Populations Practicum, Croyden Avenue School, Kalamazoo, MI

○ Position: Instructor

○ Duration: August, 2008 - April, 2009 